Provided for non-commercial research and education use. Not for reproduction, distribution or commercial use.

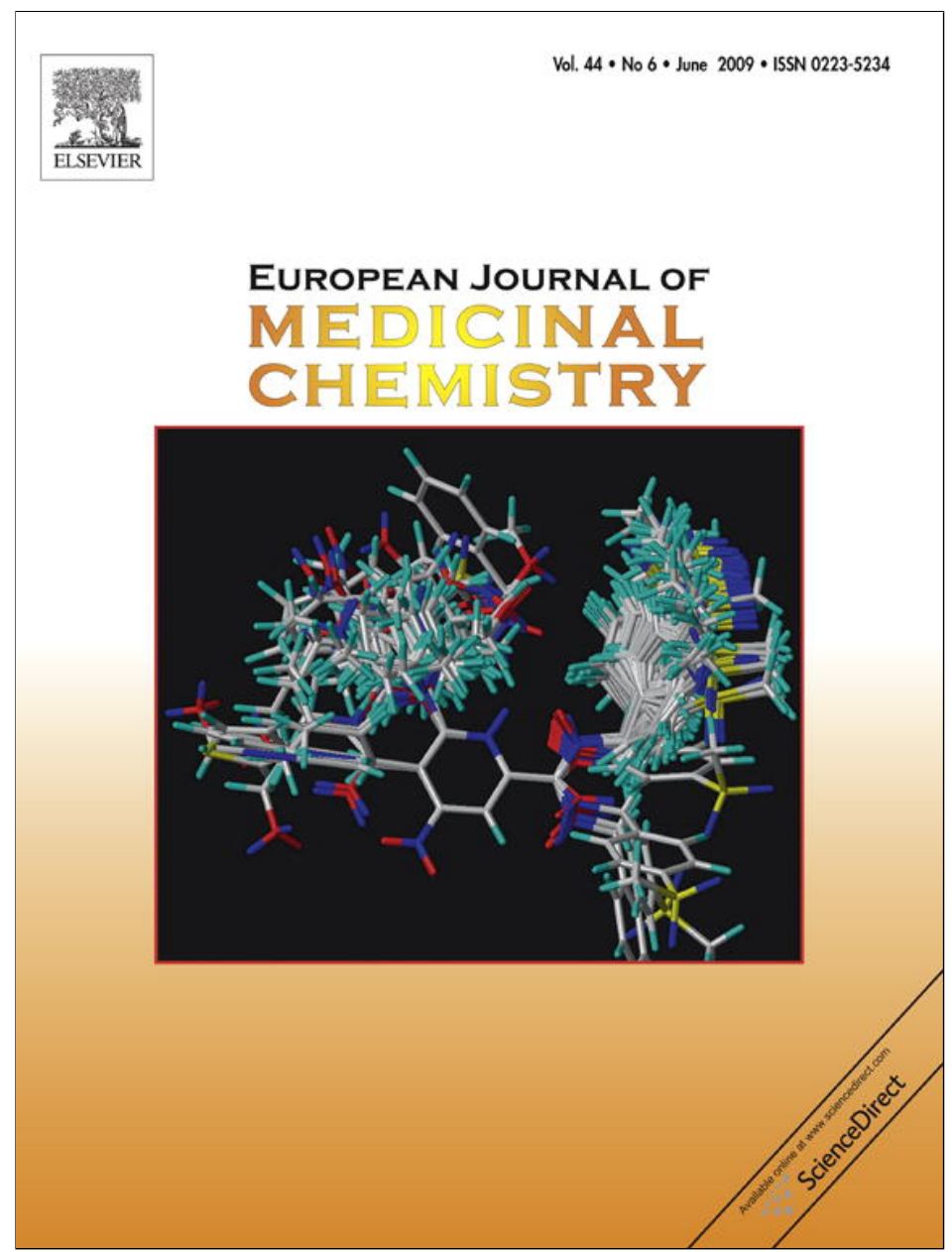

This article appeared in a journal published by Elsevier. The attached copy is furnished to the author for internal non-commercial research and education use, including for instruction at the authors institution and sharing with colleagues.

Other uses, including reproduction and distribution, or selling or licensing copies, or posting to personal, institutional or third party websites are prohibited.

In most cases authors are permitted to post their version of the article (e.g. in Word or Tex form) to their personal website or institutional repository. Authors requiring further information regarding Elsevier's archiving and manuscript policies are encouraged to visit:

http://www.elsevier.com/copyright 
Original article

\title{
Primaquine dipeptide derivatives bearing an imidazolidin-4-one moiety at the $N$-terminus as potential antimalarial prodrugs
}

\author{
Nuno Vale ${ }^{\mathrm{a}}$, Fátima Nogueira ${ }^{\mathrm{b}}$, Virgílio E. do Rosário ${ }^{\mathrm{b}}$, Paula Gomes ${ }^{\mathrm{a}, *}$, Rui Moreira ${ }^{\mathrm{c}, * *}$ \\ ${ }^{a}$ CIQUP, Departamento de Química, Faculdade de Ciências, Universidade do Porto, R. Campo Alegre, P-4169-007 Porto, Portugal \\ ${ }^{\mathrm{b}}$ CMDT-LA, Instituto de Higiene e Medicina Tropical, Universidade Nova de Lisboa, R. Junqueira 96, P- 1349-008 Lisboa, Portugal \\ ' iMed.UL, Faculdade de Farmácia, Universidade de Lisboa, Av. Professor Gama Pinto, P-1649-003 Lisboa, Portugal
}

\section{A R T I C L E I N F O}

\section{Article history:}

Received 19 November 2008

Received in revised form

15 January 2009

Accepted 20 January 2009

Available online 29 January 2009

\section{Keywords:}

Imidazolidin-4-ones

Prodrugs

Primaquine

Malaria

Gametocytocidal activity

\begin{abstract}
A B S T R A C T
Primaquine dipeptide derivatives bearing an imidazolidin-4-one moiety at the $\mathrm{N}$-terminus were synthesized and evaluated as potential transmission-blocking antimalarial prodrugs. All compounds were hydrolyzed to the parent dipeptide derivative of primaquine in neutral and basic solutions, with half lives ranging from 0.7 to $31 \mathrm{~h}$ at $37^{\circ} \mathrm{C}$, depending on the nature of the substituents present in the imidazolidin-4-one moiety and in the C-terminal amino acid directly coupled to primaquine. The antimalarial activity was studied for selected compounds using a model consisting of Plasmodium berghei, BalbC mice and Anopheles stephensi mosquitoes. The imidazolidin-4-one derived from Ala-Ala-primaquine and acetone reduced the transmission of the infection to mosquitoes more efficiently than primaquine as shown by the significant decrease in the number of oocysts in the midguts of the mosquitoes at 10 and $50 \mu \mathrm{mol} / \mathrm{kg}$ when compared to the control.
\end{abstract}

(c) 2009 Elsevier Masson SAS. All rights reserved.

\section{Introduction}

Primaquine, $\mathbf{1}$ (Scheme 1), is the only currently available drug active against both the latent liver forms of the relapsing malaria caused by Plasmodium vivax and Plasmodium ovale and the gametocytes from all species of parasite causing human malaria $[1,2]$. This 8-aminoquinoline is also active against Pneumocystis carinii [3], Leishmania tropica [4] and Tripanosoma cruzi [5], the causing agents of Pneumocystis pneumonia (PCP), visceral leishmaniosis and Chagas's disease, respectively. However, primaquine presents a short plasma half-life (ca. $6 \mathrm{~h}$ ) [6,7], as a result of its rapid oxidative deamination to the inactive metabolite carboxyprimaquine 2 (Scheme 1) [8-12]. Blood toxicity, in particular the ability of primaquine to induce oxidation of oxyhemoglobin to methemoglobin, has been also a source of concern [13]. Primaquine causes haemolytic anemia in patients with glucose-6-phosphate dehydrogenase (G6PD) deficiency [12]. In addition, a recent report revealed that primaquine may also affect gene expression in liver when given in high doses and produce undesirable outcomes if consumed for long periods [14].

\footnotetext{
* Corresponding author. Tel.: +351 220402563; fax: +351 220402659.

** Corresponding author. Tel.: +351 217946477; fax: +351 217946470.

E-mail addresses: pgomes@fc.up.pt (P. Gomes), rmoreira@ff.ul.pt (R. Moreira).
}

Peptide and amino acid derivatives of primaquine have been prepared to reduce toxicity of the parent drug as well as to suppress the metabolic pathway leading to 2 [15-18]. Despite the improved activity/toxicity ratio, most of these derivatives are rapidly hydrolyzed to primaquine by aminopeptidases and endopeptidases [16,18], suggesting that they might undergo extensive hydrolysis to the parent drug in the intestinal lumen when given orally. Imidazolidin4-one formation was introduced as a useful prodrug approach to protect the $\mathrm{N}$-terminal amino acid residue of di-, tri- and pentapeptides against aminopeptidase-catalyzed hydrolysis [19-22]. The synthetic approaches for the preparation of imidazolidin-4-ones involve the reaction of the peptide with an aldehyde or ketone followed by intramolecular cyclization. Recently, we prepared imidazolidin-4-ones, 3 (Scheme 1), as potential peptidase-stable prodrugs of amino acid derivatives of primaquine [23-25]. Compounds 3 displayed gametocytocidal activity against Plasmodium berghei comparable to that of primaquine, as well as antiplasmodial activity against Plasmodium falciparum, but presented low aqueous solubility and, unexpectedly, high stability in $\mathrm{pH} 7.4$ buffer (half lives for hydrolysis typically higher than $12 \mathrm{~h}$ ), i.e. they cannot be considered as prodrugs $[24,26]$. To overcome the problem of poor aqueous solubility displayed by compounds 3 , we decided to incorporate the imidazolidin4-one moiety at the $C$-terminus of a dipeptide backbone coupled to the parent drug, e.g.4 (Scheme 1). However, these imidazolidin-4-one peptidomimetics are extremely stable, both in human plasma and in $\mathrm{pH} 7.4$ buffer, as a result of $N^{1}$-acylation [27]. The hydrolysis of 
<smiles>[R]CCC(C)Nc1cc(OC)cc2cccnc12</smiles><smiles>[R]C(=O)ON</smiles>

Scheme 1.

imidazolidin-4-ones in neutral and basic media occurs via an $S_{N} 1$ type mechanism $[20,26]$ which involves the departure of an amide leaving group and formation of an iminium ion at $N^{1}$. Thus, removing the nucleophilicity of the $N^{1}$-nitrogen atom by acylation virtually turns compounds 4 unreactive. With the objective of developing prodrugs capable of reverting to the parent dipeptidyl primaquine with half lives adequate for oral administration, we decided to incorporate the imidazolidin-4-one moiety in the $\mathrm{N}$-terminus of the dipeptide backbone, e.g. 5 (Scheme 2). We now report the synthesis, evaluation of the chemical reactivity and antimalarial activity of novel imidazolidin-4-one derivatives of primaquine, $\mathbf{5}$ (Table 1 ).

\section{Chemistry}

The synthesis of imidazolidin-4-one prodrugs 5 is illustrated in Scheme 2. Briefly, primaquine reacted with the appropriate $N^{\alpha}$-Bocprotected amino acid (BocA $A^{1} \mathrm{OH}$ ) using HOBt/DIPCI or HOBt/DCCI methods. The corresponding $N^{\alpha}$-Boc-protected primaquine amino acid amides (6a-d) were isolated, Boc removed with neat trifluoroacetic acid (TFA) and the resulting trifluoroacetates were converted into the corresponding free bases, 7a-d, with sodium carbonate. Compounds 7 were reacted with the second $N^{\alpha}$-Bocprotected amino acid (BocAA ${ }^{4} \mathrm{OH}$ ) in the presence of triethylamine (TEA) and HOBt/DIPCI or HOBt/DCCI, to yield the protected primaquine dipeptide amides $8 \mathbf{a}-\mathbf{i}$. These were converted to the deprotected products $(\mathbf{9 a}-\mathbf{i})$ again with neat TFA followed by treatment with sodium carbonate. Finally, compounds 9 were converted into the corresponding imidazolidin-4-ones, $\mathbf{5 a}-\mathbf{s}$ (Table 1 ), by reaction with the appropriate symmetric ketone.

The structure of imidazolidin-4-ones 5 follows from their spectroscopic data, which reveal the presence of two diastereomers resulting from using racemic primaquine as starting material. For example, the imidazolidin-4-one C-2 methyl proton signals of $\mathbf{5 d}$ and 5e clearly appear as two sets of two singlets with overall $1: 1: 1: 1$ integration. Similarly, the two methyl groups at C-2 are often visible as four signals in the ${ }^{13} \mathrm{C}$ NMR spectra. In addition, the ${ }^{1} \mathrm{H}$ NMR signal of the methylene protons on the glycine residue linked to primaquine in $\mathbf{5 b}-\mathbf{e}, \mathbf{5 m}-\mathbf{n}$ and $\mathbf{5 q}-\mathbf{s}$ reveals the diastereotopic nature of the two protons, which appear as an AB system at $\delta$ ca. $4 \mathrm{ppm}$, with ${ }^{2} \mathrm{~J}$ ca. $15 \mathrm{~Hz}$. Similar observations were recently reported for the analogous peptidomimetic imidazolidin-4-ones 4 [27]. It should be outlined that identical spectroscopic behavior had already been found for the Boc-protected precursors 6, whose conversion into compounds $\mathbf{5}$ is carried out by standard $N^{\alpha}$-Bocamino acid acidolytic deprotection methods known to preserve the chiral purity of amino acids, peptides and other amino acid derivatives. In fact, it is well established that in what concerns chiral stability of their $C^{\alpha}$, amino acids and their derivatives are fairly insensitive to acids $[28,29]$.

Yields for the cyclization step range from reasonable to good and seem to be dependent on the nature of the $\mathrm{R}^{1}$ substituent present in intermediates $\mathbf{9}$. For example, the cyclization yield is significantly lower when a bulky amino acid such as Leu or Phe is present as the $C$-terminal residue (i.e. $R^{1}$ ) of the dipeptide backbone than when is present as the $N$-terminal residue (i.e. $\mathrm{R}^{4}$ ) (e.g. $\mathbf{5 h}$ versus $\mathbf{5 d}$ and $\mathbf{5 1}$ versus 5n). This effect might reflect the steric requirements for the cyclization of imine, $\mathbf{1 0}$ (Scheme 3 ), formed from the reaction of the amino group in $\mathbf{9}$ with the appropriate ketone [23,30,31]. It can be seen that conformation $\mathbf{A}$ (Scheme 3 ) of the imine $\mathbf{1 0}$ presents some repulsion between the $R^{1}$ group and the $R^{2}$ and $R^{3}$ substituents, thus favouring reactions in which $R^{1}=H$. Bulkier $R^{4}$ substituents might also favour cyclization of the imine, as they force the amide nitrogen atom to get in closer proximity to the imine carbon atom. For example, $\mathbf{5 d}\left(\mathrm{R}^{1}=\mathrm{H}, \mathrm{R}^{4}=\mathrm{Bu}^{i}\right)$ was formed in $75 \%$ yield, while $5 a\left(R^{1}=R^{4}=H\right)$ was formed only in $41 \%$ yield. Similar observations can be made for $\mathbf{5 f}$ versus $\mathbf{5 g}$ and for $\mathbf{5 0}$ versus $\mathbf{5 p}$.

\section{Results and discussion}

\subsection{Kinetics and products of hydrolysis}

As revealed by HPLC analysis, compounds $\mathbf{5}$ hydrolyze quantitatively at $37^{\circ} \mathrm{C}$ to the corresponding dipeptide derivative $\mathbf{9}$ over the $\mathrm{pH}$ range $0.5-12$. Products 9 were stable in these conditions and in the time-scale of the decomposition of $\mathbf{5}$. The rates of hydrolyses of imidazolidin-4-ones $\mathbf{5}$ at a fixed $\mathrm{pH}$ value were found to be independent of buffer concentration over a 10 -fold buffer concentration range, indicating the absence of general acid or base catalysis (e.g. Table 2). The influence of $\mathrm{pH}$ on the rate of hydrolysis is shown in Fig. 1 for compounds 5a and 5s, where the logarithm of the observed pseudo-first-order rate constant, $k_{\text {obs }}$, is plotted against $\mathrm{pH}$. The $\mathrm{pH}$-rate profiles for compounds $\mathbf{5}$ have a sigmoid shape, with two $\mathrm{pH}$-independent regions. Such sigmoid $\mathrm{pH}$-rate profile have been reported for other imidazolidin-4-ones [19,32] as well as for their acyclic counterparts, $N$-Mannich bases [33], and can be accounted for by assuming that both the protonated, $\mathrm{SH}^{+}$, and the unionized, $\mathrm{S}$, forms of the substrate undergo spontaneous hydrolysis (Scheme 4). The best computer fit (solid line) to the experimental data for $\mathbf{5 a}$ and $\mathbf{5 s}$ in Fig. 1 was achieved using Eq. (1): 

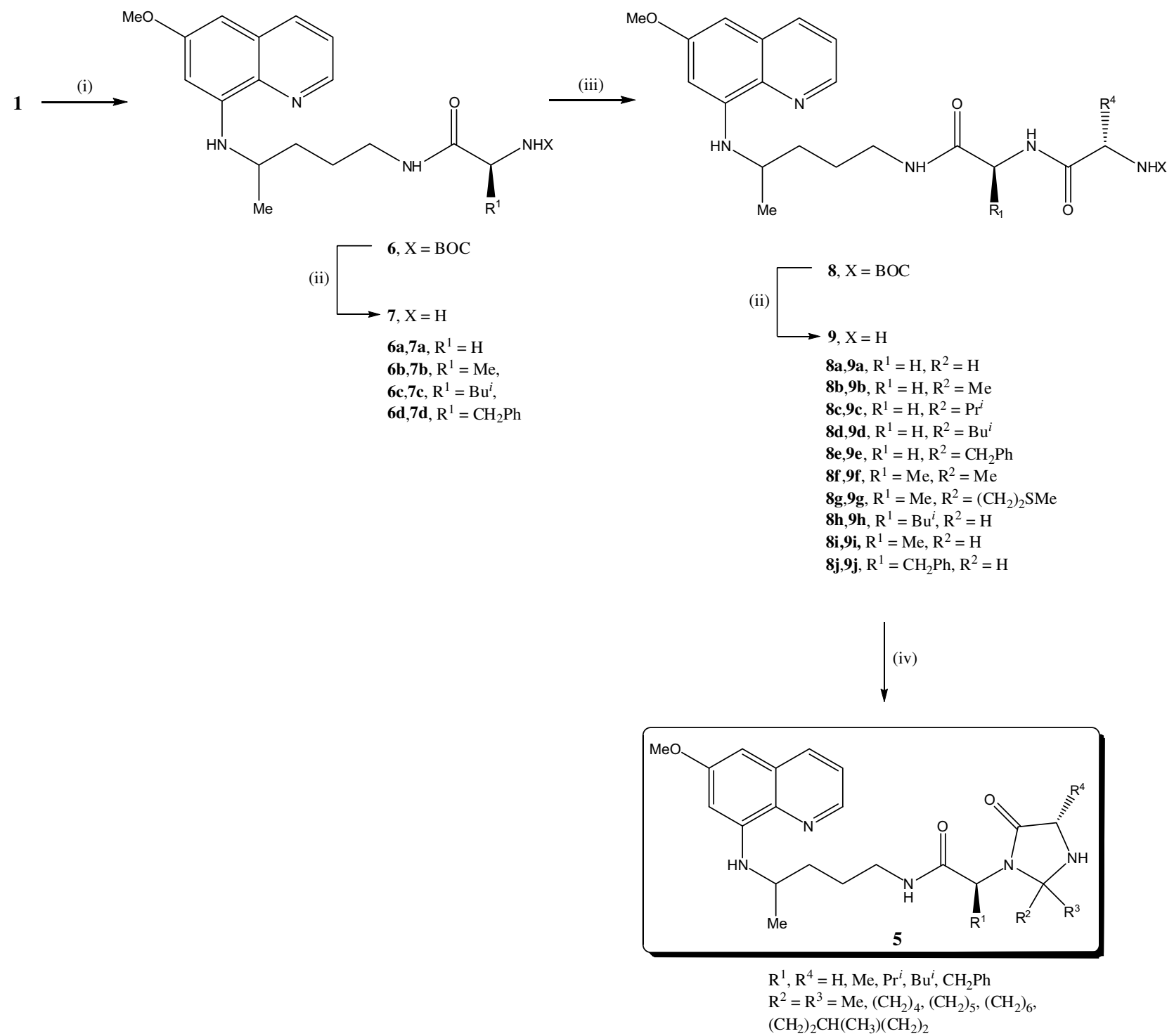

Scheme 2. Legend: (i) BocAA ${ }^{1} \mathrm{OH}$, DCCI or DIPCI, HOBt, TEA, DCM, $0{ }^{\circ} \mathrm{C}$ to r.t.; (ii) neat TFA, aq. $30 \% \mathrm{Na}_{2} \mathrm{CO}_{3}$, r.t.; (iii) 7 , $\mathrm{BocAA}{ }^{4} \mathrm{OH}$, DCCI or DIPCI, $\mathrm{HOBt}$, TEA, DCM, $0{ }^{\circ} \mathrm{C}$ to r.t.; (iv) $\mathbf{9}$, $\mathrm{R}^{2} \mathrm{COR}^{3}$, TEA, MeOH, reflux.

$k_{1}=k_{\text {neut }} \frac{K_{\mathrm{a}}}{K_{\mathrm{a}}+\left[\mathrm{H}^{+}\right]}+k_{\text {prot }} \frac{\left[\mathrm{H}^{+}\right]}{K_{\mathrm{a}}+\left[\mathrm{H}^{+}\right]}$

where $k_{\text {neut }}$ and $k_{\text {prot }}$ are the apparent first-order rate constants for the decomposition of neutral and protonated forms of $\mathbf{5}, K_{\mathrm{a}}$ is the acid dissociation constant of the protonated $\mathbf{5}$, and $\left[\mathrm{H}^{+}\right] /\left(K_{\mathrm{a}}+\left[\mathrm{H}^{+}\right]\right)$ and $K_{\mathrm{a}} /\left(K_{\mathrm{a}}+\left[\mathrm{H}^{+}\right]\right)$represent, respectively, the fraction of the protonated and neutral forms of $\mathbf{5}$ present in solution. The $k_{\text {neut }}$ values derived either from the $\mathrm{pH}$-rate profiles or determined at $\mathrm{pH}$ 8 are presented in Table 1 . The kinetically determined $\mathrm{p} K_{\mathrm{a}}$ values for $\mathbf{5 a}$ and $\mathbf{5 s}$ are 3.78 and 3.06, respectively, i.e. ca. 4 units lower that those of Gly-Gly and Phe-Gly ( $\mathrm{p} K_{\mathrm{a}} 8.2$ and 7.6, respectively [34]). A similar observation has been reported for imidazolidin-4-ones derived from peptides [20].

\subsection{Structural effects on chemical reactivity}

The imidazolidin-4-one moiety. Inspection of the kinetic data presented in Table 1 reveals that the $\mathrm{pH}$-independent pathway rate constant for the neutral prodrug, $k_{\text {neut }}$ (Scheme 4 ), has a small dependence on the size of the amino acid substituent $R^{4}$ at the imidazolidin-4-one C-5. For example, the order of half lives for the AAGly-PQ series derived from acetone is Gly-Gly-PQ $\mathbf{5 a}>$ Ala-Gly-PQ $\mathbf{5 b} \approx \mathrm{Phe}-\mathrm{Gly}-\mathrm{PQ}, \mathbf{5 e}>$ Val-Gly-PQ $\mathbf{5 c}$ with $\mathbf{5 a}$ being only ca. 10 times more reactive than $\mathbf{5 c}$. The exception is compound $\mathbf{5 d}$, derived from Leu-Gly-PQ and acetone, which is more reactive than expected based on the size of the Leu side chain, which might reflect the importance of polar effects on reactivity. The decrease of $k_{\text {neut }}$ with the size of the amino acid substituent $\mathrm{R}^{4}$ at the imidazolidin-4-one $\mathrm{C}-5$ is also observable for the cyclohexanone series: Gly-Gly-PQ $\mathbf{5 i}>$ Ala-Gly$\mathrm{PQ} \mathbf{5 m}>$ Phe-Gly-PQ, 5n. These results are consistent with those reported for imidazolidin-4-ones based on amino acid derivatives of primaquine and for imidazolidin-4-ones derived from dipeptides $[20,26]$ and can be ascribed to unfavourable steric interactions between the amino acid substituent and the $\mathrm{R}^{2}$ and $\mathrm{R}^{3}$ substituents in the iminium ion (i.e. the protonated form of 10; Scheme 3).

The rate data presented in Table 1 show that the nature of the substituents at C-2 of the imidazolidin-4-one moiety, and thus the ketone starting material, also affects the reactivity of the neutral form of the imidazolidin-4-ones $\mathbf{5}$. The order of reactivity $\left(k_{\text {neut }}\right)$ for 
the Phe-Gly-PQ imidazolidin-4-ones, according to the ketone starting material, is cycloheptanone $>$ cyclopentanone $>$ cyclohexanone $>$ acetone, the cycloheptanone compound $\mathbf{5 s}$ being ca. 20 times more reactive than its acetone counterpart, 5e. A similar trend has been reported for imidazolidin-4-ones derived from Gly-PQ 3 [26], and from enkephalins, 11.[21] A good correlation $\left(r^{2}=0.99\right.$, Fig. 2$)$ was observed between the $\log k_{\text {neut }}$ values for compounds $5 \mathbf{e}, \mathbf{n}, \mathbf{q}, \mathbf{r}$ and those of their counterparts 11. This strongly suggests that decomposition of $\mathbf{5}$ and $\mathbf{1 1}$ follow similar pathways and present the same structural requirements. The higher reactivity of the seven- and five-membered ring derivatives, 5s and 5r, when compared with the six- membered ring, 5n, can be ascribed to a decrease in internal strain resulting from a change in coordination number of the imidazolidin-4-one C-2 carbon atom from four to three in the five-member ring-opening process. A similar observation was reported for compounds 3. [26]. mosquitoes by interference with the cycle in these insects $[35,36]$. Compound $\mathbf{5 f}$ was the most potent compound at both dose levels, reducing significantly $(P<0.05)$ the sporogonic development of $P$. berghei when compared with the control. Notably, $\mathbf{5 f}$ was more potent than primaquine, inhibiting almost completely the production of oocysts at $50 \mu \mathrm{mol} / \mathrm{kg}$. Compound $\mathbf{5 b}$ was the least active in this screen. A dose of $10 \mu \mathrm{mol} / \mathrm{kg}$ of $5 \mathbf{b}$ did not significantly $(P>0.05)$ affect oocyst production when compared with the control. This lack of activity is unlikely to reflect the slow hydrolysis of $\mathbf{5 b}$ to the parent active dipeptide derivative, Ala-Gly-PQ (more than $99 \%$ of $\mathbf{5 b}$ is converted to the active at the time of oocyst counting), but might reflect the poor gametocytocidal activity of the parent dipeptide at lower doses [18]. The decomposition of compounds $\mathbf{5 a}, \mathbf{5 b}$ and $\mathbf{5 f}$ was studied in plasma obtained from non-infected mice, diluted to $80 \%(\mathrm{v} / \mathrm{v})$ with $\mathrm{pH} 7.4$ isotonic phosphate buffer, at $37^{\circ} \mathrm{C}$. These compounds decomposed to corresponding dipeptidyl derivatives 9

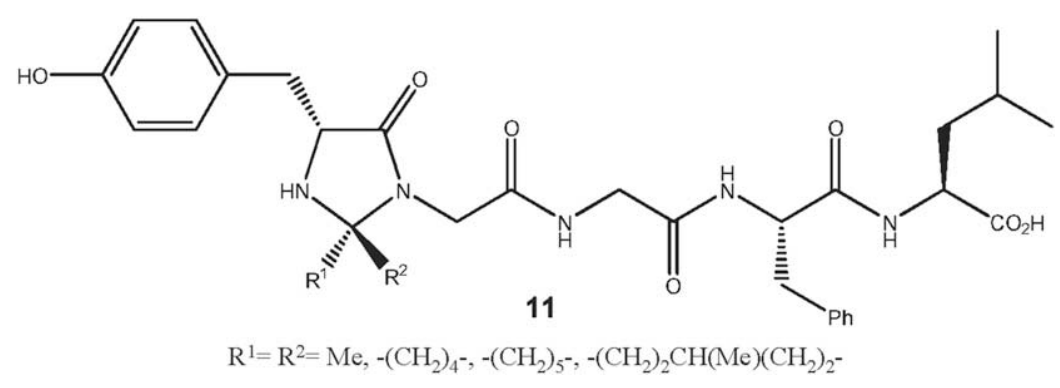

The C-terminal amino acid. The effect of $\alpha$-carbon atom substituents $\left(R^{1}\right)$ in the $C$-terminal amino acid on the reactivity depends on the nature of the $\mathrm{R}^{4}$ substituent at imidazolidin-4-one C-5 position. For example, the order of $k_{\text {neut }}$ for the Gly-AA ${ }^{1}-\mathrm{PQ}$ series (i.e. $\mathrm{R}^{4}=\mathrm{H}$ ) derived from cyclohexanone is Gly-Gly-PQ $\mathbf{5 i}>$ GlyPhe-PQ $\mathbf{5 1}>$ Gly-Leu-PQ $\mathbf{5 k} \approx$ Gly-Ala-PQ $\mathbf{5 j}$, with $\mathbf{5 i}$ being only ca. 4 times more reactive than $\mathbf{5 j}$. This suggests that electrondonating $\mathrm{R}^{1}$ substituents, although having only a minor influence on the stability, retard the decomposition of imidazolidin-4-ones 5 in neutral and basic conditions $\left(\sigma^{*} \mathrm{H}=0.49 ; \sigma^{*} \mathrm{CH}_{2} \mathrm{Ph}=0.21\right.$; $\sigma^{*} \mathrm{Me}=0 ; \sigma^{*} \mathrm{Bu}^{i}=-0.12$ ). In contrast, compound 5o, derived from Ala-Ala-PQ and cyclohexanone, is ca. 7 times more reactive than its Ala-Gly-PQ counterpart, 5m. Similarly, compound $\mathbf{5 f}$, derived from Ala-Ala-PQ and acetone, is ca. 15 times more reactive than its Ala-Gly-PQ counterpart, $\mathbf{5 b}$. This is consistent with the finding that rate of decomposition of imidazolidin-4-ones derived from dipeptides is accelerated when sterically-hindered amino acids are present as $C$-terminal residues [20]. For example, the imidazolidin-4-one derived from Phe-Ala and acetone is ca. 37 times more reactive than its Phe-Gly counterpart [20].

\subsection{Antimalarial activity}

The potential of compounds $\mathbf{5 a}, \mathbf{5 b}$ and $\mathbf{5 f}$ (i.e. half lives of 3, 16 and $1 \mathrm{~h}$, respectively) to prevent the transmission of malaria was studied using a model consisting of BalbC mice infected with $P$. berghei and Anopheles stephensi mosquitoes and compared to that of primaquine. The antimalarial activity was assessed based on the percentage of mosquitoes with oocysts and the mean number of oocysts per infected mosquito (Table 3 ). Although this model cannot specifically attribute the drug effect to either gametocytocidal activity or sporontocidal activity, it can clearly show if compounds are effective at interrupting the transmission of the infection to in plasma, with first-order rate constants identical to those for the $k_{\text {neut }}$ pathway (Table 1 ), indicating that plasma enzymes do not catalyse the reaction.

\section{Conclusions}

Primaquine dipeptide derivatives, 5, bearing an imidazolidin-4one moiety at the $\mathrm{N}$-terminus are readily hydrolyzed to the parent dipeptide derivatives of primaquine in neutral and basic solutions, with half lives ranging from 0.7 to $31 \mathrm{~h}$ at $37^{\circ} \mathrm{C}$, depending on the substituents at the imidazolidin-4-one moiety as well as on the C-terminal amino acid directly coupled to primaquine. The most critical factor is the substituent at the imidazolidin-4-one C-2 position, i.e. those derived from the ketone starting material. Imidazolidin-4ones derived from acetone are generally more stable than their counterparts derived from cyclohexanone or cyclopentanone, while the most reactive prodrug is the one derived from cycloheptanone. Importantly, decomposition is not catalyzed by plasma enzymes. Compounds 5 are capable of reducing the transmission of the infection to mosquitoes as efficiently as primaquine and the corresponding parent dipeptide derivatives. In conclusion, these results herein presented suggest that imidazolidin-4-ones $\mathbf{5}$ present a stability profile similar to that of imidazolidin-4-ones derived from di- and tripeptides, and thus may be a useful prodrug approach to protect the $\mathrm{N}$-terminal amino acid residue against enzymatic cleavage by aminopeptidases.

\section{Experimental protocols}

\subsection{General}

Boc-amino acids were from Bachem, solvents were all of p.a. quality from Merck and were dried over pre-activated $3 \AA$ molecular sieves prior to utilization. All remaining reactants were from 
Table 1

Yields of imidazolidin-4-ones 5 (from precursors $\mathbf{9}$ ) and $\mathrm{pH}$-independent pathway rate constant constants, $k_{\text {neut }}$, for the decomposition of neutral prodrugs $\mathbf{5}$ at $37^{\circ} \mathrm{C}$.

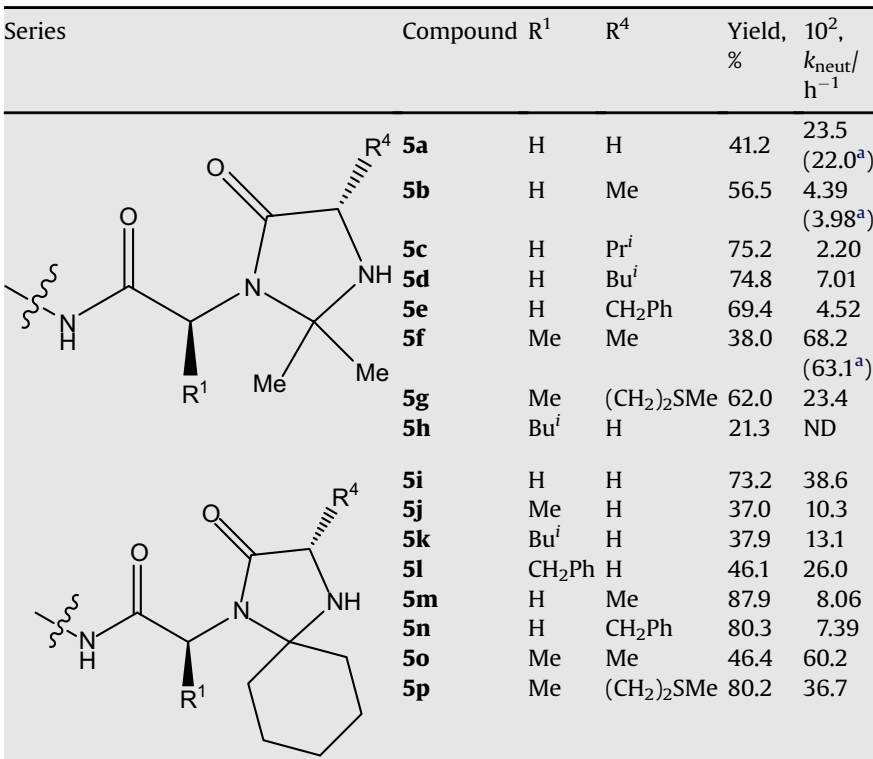<smiles>[R]C1NC2(CCC(C)CC2)N([C@@H]([R7])C(=O)NS(C)(F)F)C1=O</smiles>

$\mathrm{H} \quad \mathrm{CH}_{2} \mathrm{Ph} \quad 61.8 \quad 5.30$<smiles>[R]C1NC2(CCCC2)N([C@@H]([R1])C(=O)NS(C)(C)C)C1=O</smiles>
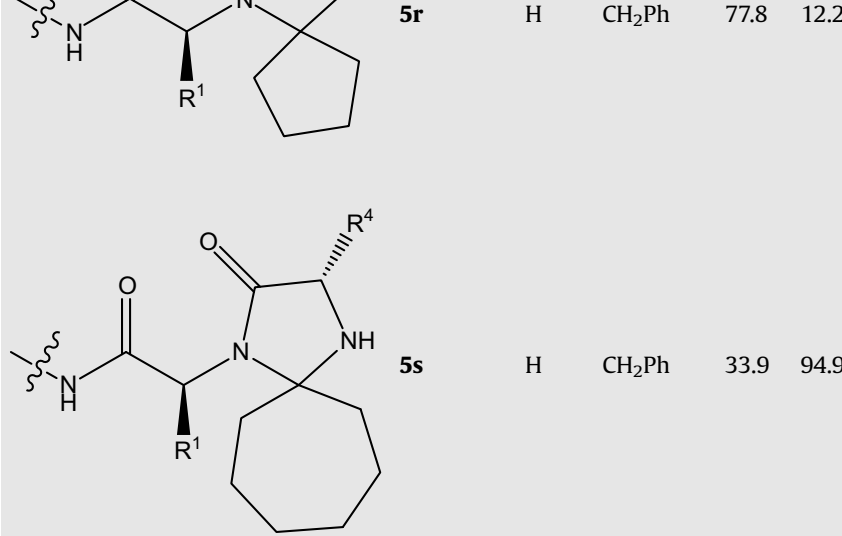

$5 s$

$\mathrm{H}$

$\mathrm{CH}_{2} \mathrm{Ph}$

33.9

94.9

a First-order rate constant for the hydrolysis in $80 \%$ human plasma in $\mathrm{pH} 7.4$ phosphate buffer at $37^{\circ} \mathrm{C}$.

Sigma-Aldrich. Silica-gel 60 plates (Merck $\mathrm{F}_{254}$ ) were used for thinlayer chromatography. Nuclear magnetic resonance (NMR) spectra were acquired on a Bruker AMX 300 spectrometer from solutions of the compounds in deuterated chloroform $\left(\mathrm{CDCl}_{3}\right)$ having<smiles>[R]C([R])=N[C@@H]([Z7])C(=O)N[C@@H]([R7])C(=O)NC(C)(C)C</smiles>

10

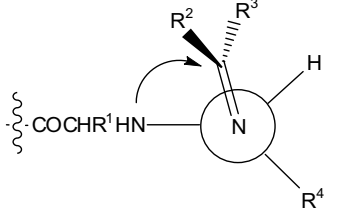

A
Scheme 3.

tetramethylsilane (TMS) as internal reference: ${ }^{1} \mathrm{H}$ and ${ }^{13} \mathrm{C}$ chemical shifts are given in parts per million ( $\mathrm{ppm}$ ) and proton-proton coupling constants in Hertz $(\mathrm{Hz}) ;{ }^{1} \mathrm{H}$ NMR peak multiplicity is indicated by br s (broad singlet), s (singlet), d (doublet), dd (double doublet), $\mathrm{t}$ (triplet), q (quartet), $\mathrm{m}$ (unresolved multiplet). Mass spectra (MS) were acquired by either the matrix-assisted laser desorption ionization - time-of-flight (MALDI-TOF) using either anthracene or 2,5-dihydroxybenzoic acid (DHB) as adjuvant matrices, or the electrospray ionization ion-trap (ESI-IT) techniques, on a Bruker Biflex II or a Finningan LCQ DECA XP MAX spectrometer, respectively.

\subsection{Syntheses}

\subsubsection{Synthesis of compounds $8 \boldsymbol{8}-\boldsymbol{f}$}

The appropriate PQAA ${ }^{1}$ [23] (3.1 mmol) was suspended in DCM $(30 \mathrm{~mL})$, TEA (4 eq.) was added and the mixture was stirred in an ice-water bath for $30 \mathrm{~min}$. After addition of the BocAA ${ }^{4} \mathrm{OH}$ (1.1 eq.) and HOBt (1.2 eq.), the carbodiimide (DCCI, 1.2 eq.) was slowly added to the mixture, witch was kept at $0{ }^{\circ} \mathrm{C}$ for more $2 \mathrm{~h}$. The reaction was allowed to proceed at room temperature for $2 \mathrm{~d}$ with periodic monitoring by TLC. A second stepwise addition of carbodiimide (1.2 eq.) was made, and the reaction prolonged for further $3 \mathrm{~d}$. The solid phase formed was removed by suction filtration and identified as the carbodiimide-derived urea (DCU). The filtrate was evaporated to dryness and the residue dissolved in the minimum amount of warm acetone; the resulting solution was stored overnight at $4{ }^{\circ} \mathrm{C}$ and the urea precipitated was again removed by suction filtration. The filtrate was evaporated to dryness and the residue submitted to column chromatography on silica-gel, using DCM/acetone mixtures as eluents. Products were isolated as yellow-orange oils in $50-79 \%$ yields and successfully characterized by MS and NMR (see Supporting information).

\subsubsection{Synthesis of compounds $\mathbf{9 a - f}$}

Compounds $\mathbf{8}$ were dissolved in a small volume of neat trifluoroacetic acid (TFA, ca. $5 \mathrm{~mL}$ ) and the deprotection reactions allowed to proceed for $1-2 \mathrm{~h}$ at room temperature. Excess TFA was neutralized by dropwise addition of aqueous $\mathrm{Na}_{2} \mathrm{CO}_{3}$ at $30 \%$ until $\mathrm{pH} \mathrm{9}$; the supernatant oily phase formed in this process was extracted six times with $10 \mathrm{~mL}$ portions of chloroform and the

Table 2

First-order rate constants, $k_{\mathrm{obs}}$, for the hydrolysis of $\mathbf{5 s}$ in acetate and $\mathbf{5 a}$ in phosphate buffers at $37^{\circ} \mathrm{C}$, with ionic strength maintained at $0.5 \mathrm{~mol} \mathrm{dm}^{-3}$ by addition of $\mathrm{NaClO}_{4}$

\begin{tabular}{lllll}
\hline Compd & Buffer & [Buffer], $\mathrm{mol} \mathrm{dm}^{-3}$ & $\mathrm{pH}$ & $10^{2} k_{\text {obs }}, \mathrm{h}^{-1}$ \\
\hline $\mathbf{5 s}$ & $\mathrm{CH}_{3} \mathrm{CO}_{2} \mathrm{H}$ & 0.005 & 4.45 & 94.7 \\
& & 0.010 & 4.47 & 95.4 \\
& & 0.050 & 4.42 & 95.7 \\
$\mathbf{5 a}$ & $\mathrm{H}_{2} \mathrm{PO}_{4}^{-}$ & 0.002 & 6.93 & 24.6 \\
& & 0.005 & 6.95 & 23.8 \\
& & 0.010 & 6.96 & 25.5 \\
\hline
\end{tabular}




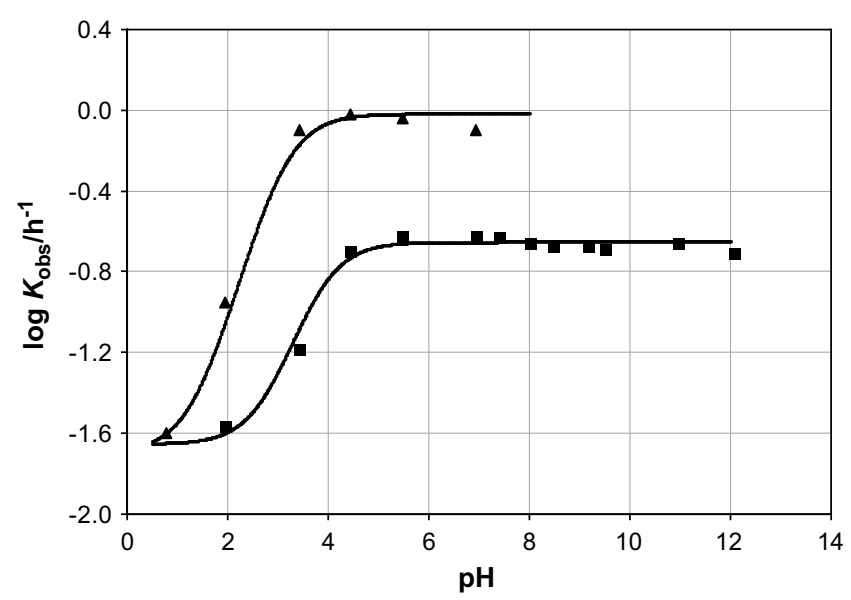

Fig. 1. pH-rate profiles for the hydrolysis of the imidazolidin-4-ones $\mathbf{5 a}(\boldsymbol{a})$ and $\mathbf{5 s}$ $(\boldsymbol{A})$ in aqueous solutions at $37^{\circ} \mathrm{C}$.

organic phases pooled, dried over anhydrous $\mathrm{MgSO}_{4}$ and evaporated to dryness. Products $\mathbf{9}$ were thus isolated as yellow-orange oils in $84-99 \%$ yields and successfully characterized by MS an NMR (see Supporting information).

\subsubsection{Preparation of the target compounds $\mathbf{5 a}-\mathbf{s}$}

Compounds $\mathbf{9}$ were mixed with an excess (2 eq.) of the appropriate ketone (propanone, cyclohexanone, cycloheptanone and 4methylciclohexanone) and TEA (1 eq.) in dry methanol (20 mL) and the mixture refluxed for $3 \mathrm{~d}$ in the presence of $4 \AA$ A molecular sieves $(1 \mathrm{~g})$. The reaction was monitored by TLC and ketone was re-added (1 eq.) once per day. The molecular sieves were removed by decantation and the solution evaporated to dryness. The oily residue was submitted to column chromatography on silica-gel, eluted with appropriate solvents. Fractions containing the chromatographically homogeneous product were pooled and evaporated to dryness, yielding $\mathbf{5 a - s}$ as yellow-orange oils (21-88\%) that were analyzed by MS and NMR, as detailed below.

3-\{7-[(6-Methoxyquinolin-8-yl)amino]-3-aza-2-oxooctyl $\}-2,2-$ dimethylimidazolidin-4-one, 5a. Yield $41 \% ; \delta_{\mathrm{H}}\left(\mathrm{CDCl}_{3}, 300 \mathrm{MHz}\right) 8.53$ (dd, J=4.13 Hz, J=1.58 Hz; 1H, Q2); 7.92 (dd, J = $8.26 \mathrm{~Hz}$,
$\mathrm{J}=1.39 \mathrm{~Hz} ; 1 \mathrm{H}, \mathrm{Q} 4) ; 7.31$ (dd, $\mathrm{J}=8.25 \mathrm{~Hz}, \mathrm{~J}=4.17 \mathrm{~Hz} ; 1 \mathrm{H}, \mathrm{Q} 3) ; 6.60$ $\left(\mathrm{m}, 1 \mathrm{H},-\left(\mathrm{CH}_{2}\right)_{3}-\mathrm{NH}-\mathrm{CO}-\right) ; 6.34(\mathrm{~d}, \mathrm{~J}=2.38 \mathrm{~Hz} ; 1 \mathrm{H}, \mathrm{Q} 5) ; 6.26(\mathrm{~d}$, $\mathrm{J}=2.32 \mathrm{~Hz} ; 1 \mathrm{H}, \mathrm{Q} 7) ; 5.98\left(\mathrm{~d}, \mathrm{~J}=8,09 \mathrm{~Hz}, 1 \mathrm{H},-\mathrm{NH}-\mathrm{CH}\left(\mathrm{CH}_{3}\right)-\mathrm{CH}_{2}-\right)$; 3.89 (s; $\left.3 \mathrm{H}, \mathrm{CH}_{3}-\mathrm{O}-\right)$; 3.77 (s; $\left.2 \mathrm{H},-\mathrm{NH}-\mathrm{CO}-\mathrm{CH}_{2}-\mathrm{N}-\right)$; 3.65-3.55 (m; $\left.1 \mathrm{H},-\mathrm{NH}-\mathrm{CH}\left(\mathrm{CH}_{3}\right)-\mathrm{CH}_{2}-\right)$; $3.46\left(\mathrm{~s} ; 2 \mathrm{H},-\mathrm{N}-\mathrm{CO}-\mathrm{CH}_{2}-\mathrm{NH}-\right)$; $3.30-$ $3.22\left(\mathrm{~m} ; 2 \mathrm{H},-\left(\mathrm{CH}_{2}\right)_{2}-\mathrm{CH}_{2}-\right) ; 1.90$ (bs; $\left.1 \mathrm{H},-\mathrm{CO}-\mathrm{CH}_{2}-\mathrm{NH}-\right) ; 1.72-$ $1.58\left(\mathrm{~m} ; 4 \mathrm{H},-\mathrm{CH}_{2}-\mathrm{CH}_{2}-\mathrm{CH}_{2}-\right)$; 1.33 and 1.31 ( $+\mathrm{s} ; 6 \mathrm{H},-\mathrm{CH}_{2}-\mathrm{NH}-$ $\left.\mathrm{C}\left(\mathrm{CH}_{3}\right)_{2}-\mathrm{N}-\right) ; 1.29\left(\mathrm{~d}, \mathrm{~J}=6.56 \mathrm{~Hz} ; 3 \mathrm{H},-\mathrm{NH}-\mathrm{CH}\left(\mathrm{CH}_{3}\right)-\mathrm{CH}_{2}-\right)$. $\delta_{\mathrm{C}}$ $\left(\mathrm{CDCl}_{3}, 75 \mathrm{MHz}\right) 174.66\left(-\mathrm{NH}-\mathrm{CO}-\mathrm{CH}_{2}-\right)$; $168.74\left(-\mathrm{N}-\mathrm{CO}-\mathrm{CH}_{2-}\right.$ $\mathrm{NH}-) ; 159.38-91.71(\mathrm{ArC}) ; 78.66\left(-\mathrm{N}-\mathrm{C}\left(\mathrm{CH}_{3}\right)_{2}-\mathrm{NH}-\right) ; 55.22\left(\mathrm{CH}_{3}-\right.$ $\mathrm{O}-)$; 48.02 (-CO-CH$-\mathrm{NH}-)$; $47.74\left(-\mathrm{NH}-\mathrm{CO}-\mathrm{CH}_{2}-\right)$; $44.79(-\mathrm{NH}-$ $\left.\mathrm{CH}\left(\mathrm{CH}_{3}\right)-\mathrm{CH}_{2}-\right)$; $39.42\left(-\left(\mathrm{CH}_{2}\right)_{2}-\mathrm{CH}_{2}-\right) ; 33.87\left(-\mathrm{CH}_{2}-\left(\mathrm{CH}_{2}\right)_{2}-\right)$; $26.13\left(-\mathrm{CH}_{2}-\mathrm{CH}_{2}-\mathrm{CH}_{2}-\right) ; 25.85\left(-\mathrm{N}-\mathrm{C}\left(\mathrm{CH}_{3}\right)_{2}-\mathrm{NH}-\right) ; 20.54(-\mathrm{NH}-$ $\left.\mathrm{CH}\left(\mathrm{CH}_{3}\right)-\mathrm{CH}_{2-}\right) . \quad \mathrm{C}_{22} \mathrm{H}_{31} \mathrm{~N}_{5} \mathrm{O}_{3} \quad\left(413.2427 \mathrm{~g} \mathrm{~mol}^{-1}\right): \mathrm{m} / \mathrm{z} \quad\left(\mathrm{MH}^{+}\right)=$ 414.2231.

3-\{7-[(6-Methoxyquinolin-8-yl)amino]-3-aza-2-oxooctyl $\}-2,2,5-$ trimethylimidazolidin-4-one, 5b. Yield $56 \% ; \delta_{\mathrm{H}}\left(\mathrm{CDCl}_{3}, 300 \mathrm{MHz}\right)$ 8.52 (dd, J = 4.24 Hz, J = $1.70 \mathrm{~Hz} ; 1 \mathrm{H}, \mathrm{Q} 2) ; 7.92$ (dd, J = 8.28 Hz, $\mathrm{J}=1.62 \mathrm{~Hz} ; 1 \mathrm{H}, \mathrm{Q} 4) ; 7.30(\mathrm{dd}, \mathrm{J}=8.27 \mathrm{~Hz}, \mathrm{~J}=4.20 \mathrm{~Hz} ; 1 \mathrm{H}, \mathrm{Q} 3) ; 6.63$ (m; $\left.1 \mathrm{H},-\mathrm{CH}_{2}-\mathrm{NH}-\mathrm{CO}-\mathrm{CH}_{2}-\right) ; 6.33(\mathrm{~d}, \mathrm{~J}=2.43 \mathrm{~Hz}, 1 \mathrm{H}, \mathrm{Q} 5) ; 6.26$ (d, $\mathrm{J}=2.38 \mathrm{~Hz} ; 1 \mathrm{H}, \mathrm{Q} 7)$; 5.99 (d, J = $8.10 \mathrm{~Hz} ; 1 \mathrm{H},-\mathrm{NH}-\mathrm{CH}\left(\mathrm{CH}_{3}\right)-\mathrm{CH}_{2}{ }^{-}$); 3.89 and $3.88(\mathrm{~d}+\mathrm{d}, \mathrm{J}=15.28 \mathrm{~Hz}, \mathrm{~J}=15.36 \mathrm{~Hz} ; 1 \mathrm{H},-\mathrm{NH}-\mathrm{CO}-\mathrm{CHH}-$ $\mathrm{N}-)$; $3.87\left(\mathrm{~s} ; 3 \mathrm{H}, \mathrm{CH}_{3}-\mathrm{O}-\right) ; 3.68$ and $3.66(\mathrm{~d}+\mathrm{d}, \mathrm{J}=15.37 \mathrm{~Hz}$, $\mathrm{J}=15.31 \mathrm{~Hz} ; \quad 1 \mathrm{H}, \quad-\mathrm{NH}-\mathrm{CO}-\mathrm{CH} H-\mathrm{N}-) ; 3.65-3.53(\mathrm{~m} ; 2 \mathrm{H}, \quad-$ $\left.\mathrm{CO}-\mathrm{CH}\left(\mathrm{CH}_{3}\right)-\mathrm{NH}-\mathrm{C}-, \quad-\mathrm{NH}-\mathrm{CH}\left(\mathrm{CH}_{3}\right)-\mathrm{CH}_{2}-\right) ; 3.33-3.18(\mathrm{~m} ; 2 \mathrm{H}$, $\left.-\left(\mathrm{CH}_{2}\right)_{2}-\mathrm{CH}_{2}-\right) ; 1.79\left(\mathrm{~m} ; 1 \mathrm{H},-\mathrm{CO}-\mathrm{CH}\left(\mathrm{CH}_{3}\right)-\mathrm{NH}-\mathrm{C}-\right) ; 1.69-1.57(\mathrm{~m}$; $\left.4 \mathrm{H},-\mathrm{CH}_{2}-\mathrm{CH}_{2}-\mathrm{CH}_{2}-\right) ; 1.40\left(\mathrm{~d}, \mathrm{~J}=3.90 \mathrm{~Hz} ; 3 \mathrm{H},-\mathrm{CO}-\mathrm{CH}\left(\mathrm{CH}_{3}\right)-\mathrm{NH}-\right.$ C-); $1.34-1.27\left(\mathrm{~m} ; 9 \mathrm{H},-\mathrm{NH}-\mathrm{C}\left(\mathrm{CH}_{3}\right)_{2}-,-\mathrm{NH}-\mathrm{CH}\left(\mathrm{CH}_{3}\right)-\mathrm{CH}_{2}-\right)$. $\delta_{\mathrm{C}}$ $\left(\mathrm{CDCl}_{3}, 75 \mathrm{MHz}\right) 176.63$ (-N-CO-CH( $\left.\mathrm{CH}_{3}\right)-$ ); 168.92 (-NH-CO$\left.\mathrm{CH}_{2}-\mathrm{N}-\right)$; $159.38-91.69(\mathrm{ArC}) ; 67.95\left(-\mathrm{N}-\mathrm{C}\left(\mathrm{CH}_{3}\right)_{2}-\mathrm{NH}-\right) ; 55.22$ $\left(\mathrm{CH}_{3}-\mathrm{O}-\right)$; 53.65 (-CO-CH$\left.\left(\mathrm{CH}_{3}\right)-\mathrm{NH}-\right)$; $47.72\left(-\mathrm{NH}-\mathrm{CH}\left(\mathrm{CH}_{3}\right)-\right.$ $\left.\mathrm{CH}_{2}-\mathrm{CH}_{2}-\right) ; 45.14$ (-CO-CH$\left.{ }_{2}-\mathrm{N}-\right)$; $39.41\left(-\left(\mathrm{CH}_{2}\right)_{2}-\mathrm{CH}_{2}-\right) ; 33.97$ $\left(-\mathrm{CH}_{2}-\left(\mathrm{CH}_{2}\right)_{2}-\right) ; \quad 27.71 \quad\left(-\mathrm{CH}_{2}-\mathrm{CH}_{2}-\mathrm{CH}_{2}-\right) ; 26.23 \quad(-\mathrm{N}-$ $\left.\mathrm{C}\left(\mathrm{CH}_{3}\right)\left(\mathrm{CH}_{3}\right)-\mathrm{NH}-\right)$; 25.37 (-N-C $\left.\left(\mathrm{CH}_{3}\right)\left(\mathrm{CH}_{3}\right)-\mathrm{NH}-\right) ; 20.58(-\mathrm{NH}-$ $\left.\mathrm{CH}\left(\mathrm{CH}_{3}\right)-\mathrm{CH}_{2}-\right) ; \quad 17.25 \quad\left(-\mathrm{CO}-\mathrm{CH}\left(\mathrm{CH}_{3}\right)-\mathrm{NH}-\right) . \quad \mathrm{C}_{23} \mathrm{H}_{33} \mathrm{~N}_{5} \mathrm{O}_{3}$ $\left(427.2583 \mathrm{~g} \mathrm{~mol}^{-1}\right): \mathrm{m} / z\left(\mathrm{MH}^{+}\right)=428.2367$.

3-\{7-[(6-Methoxyquinolin-8-yl)amino]-3-aza-2-oxooctyl\}-5-isopropyl-2,2-dimethylimidazolidin-4-one, 5c. Yield 75\%; $\delta_{\mathrm{H}}\left(\mathrm{CDCl}_{3}\right.$, $300 \mathrm{MHz}$ ) 8.46 (dd, J=4.09 Hz, J=1.31 Hz; 1H, Q2); 7.85 (dd, $\mathrm{J}=8.22 \mathrm{~Hz}, \mathrm{~J}=1.32 \mathrm{~Hz} ; 1 \mathrm{H}, \mathrm{Q} 4) ; 7.24(\mathrm{dd}, \mathrm{J}=8.23 \mathrm{~Hz}, \mathrm{~J}=4.22 \mathrm{~Hz}$; $1 \mathrm{H}, \quad \mathrm{Q} 3) ; 6.66$ and 6.64 (bs + bs; $\left.1 \mathrm{H},-\left(\mathrm{CH}_{2}\right)_{3}-\mathrm{NH}-\right) ; 6.27$<smiles>[R]C(C(=O)NC)N1C(=O)[C@@H]([Z7])[NH2+]C1([R])[R]</smiles>

$5, \mathrm{SH}^{+}$

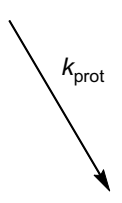<smiles>[Z2][C@H](NC(=O)[C@@H]([Z7])N)C(=O)N[14C](C)(C)C</smiles>

9<smiles>[R]C1NC([R])([R])N([C@H]([R7])C(=O)NC(C)(C)C)C1=O</smiles>

$5, S$<smiles>[Y][14CH3]</smiles><smiles>[R]C([R])=O</smiles> 


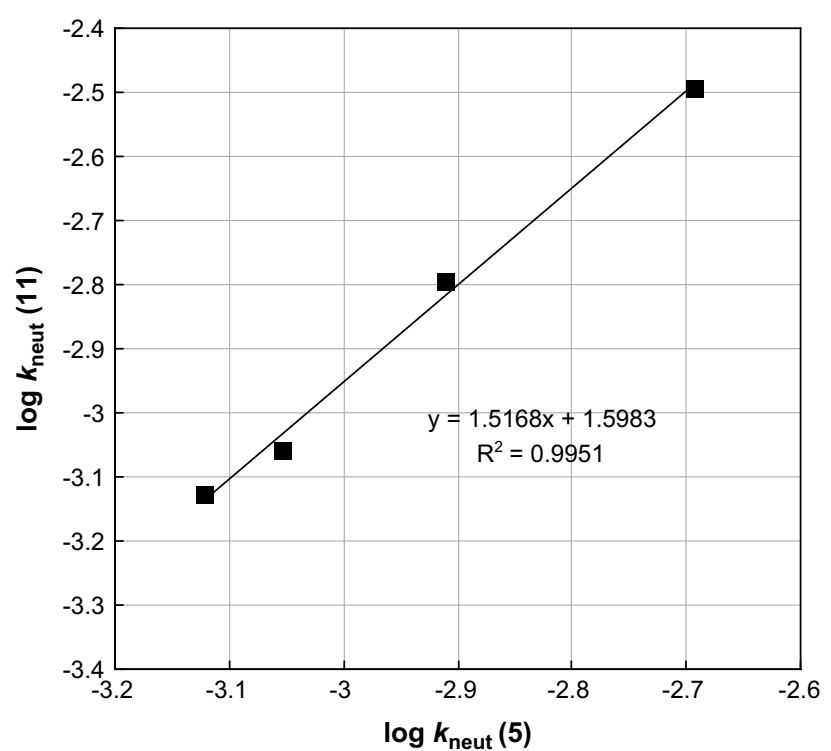

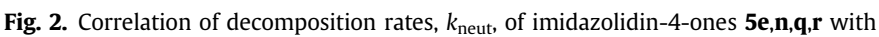
those of their enkephalin counterparts $\mathbf{1 1}$.

(d, J=2.31 Hz; 1H, Q5; $6.21(\mathrm{~d}, \mathrm{~J}=2.20 \mathrm{~Hz} ; 1 \mathrm{H}, \mathrm{Q} 7) ; 5.94$ (d, $\left.\mathrm{J}=8.28 \mathrm{~Hz} ; 1 \mathrm{H},-\mathrm{NH}-\mathrm{CH}\left(\mathrm{CH}_{3}\right)-\right) ; 3.89$ and $3.88(\mathrm{~d}+\mathrm{d}, \mathrm{J}=15.47 \mathrm{~Hz}$, $\mathrm{J}=15.45 \mathrm{~Hz} ; 1 \mathrm{H},-\mathrm{CO}-\mathrm{CHH}-) ; 3.82\left(\mathrm{~s} ; 3 \mathrm{H}, \mathrm{CH}_{3}-\mathrm{O}-\right) ; 3.58(3)$ and $3.57(9)(\mathrm{d}+\mathrm{d}, \mathrm{J}=15.61 \mathrm{~Hz}, \mathrm{~J}=15.53 \mathrm{~Hz} ; 1 \mathrm{H},-\mathrm{CO}-\mathrm{CHH}-)$; $3.55-$ $3.52(\mathrm{~m} ; 1 \mathrm{H},-\mathrm{CO}-\mathrm{CH}(\mathrm{CH}-)-\mathrm{NH}-) ; 3.44-3.42(\mathrm{~m} ; 1 \mathrm{H},-\mathrm{NH}-$ $\left.\left.\mathrm{CH}\left(\mathrm{CH}_{3}\right)-\right) ; 3.27-3.12\left(\mathrm{~m} ; 2 \mathrm{H},-\left(\mathrm{CH}_{2}\right)_{2}-\mathrm{CH}_{2}\right)^{-}\right) ; 2.09-2.05(\mathrm{~m} ; 1 \mathrm{H}$, - $\mathrm{CO}-\mathrm{CH}(\mathrm{CH}-)-\mathrm{NH}-) ; 1.64-1.49\left(\mathrm{~m} ; 4 \mathrm{H},-\mathrm{CH}_{2}-\mathrm{CH}_{2}-\mathrm{CH}_{2}-\right) ; 1.33$ (s; $\left.3 \mathrm{H},-\mathrm{C}\left(\mathrm{CH}_{3}\right)\left(\mathrm{CH}_{3}\right)-\right) ; 1.22(5)\left(\mathrm{d}, \mathrm{J}=6.39 \mathrm{~Hz} ; 3 \mathrm{H},-\mathrm{NH}-\mathrm{CH}\left(\mathrm{CH}_{3}\right)-\right)$; $1.22(2)\left(\mathrm{s} ; 3 \mathrm{H},-\mathrm{C}\left(\mathrm{CH}_{3}\right)\left(\mathrm{CH}_{3}\right)-\right) ; 0.96$ and $0.95(\mathrm{~d}+\mathrm{d}, \mathrm{J}=6.74 \mathrm{~Hz}$, $\left.\mathrm{J}=6.80 \mathrm{~Hz} ; 3 \mathrm{H},-\mathrm{CH}\left(\mathrm{CH}_{3}\right)\left(\mathrm{CH}_{3}\right)\right) ; 0.84$ and $0.81(\mathrm{~d}+\mathrm{d}, \mathrm{J}=6.82 \mathrm{~Hz}$, $\left.\mathrm{J}=6.84 \mathrm{~Hz} ; 3 \mathrm{H},-\mathrm{CH}\left(\mathrm{CH}_{3}\right)\left(\mathrm{CH}_{3}\right)\right) . \delta_{\mathrm{C}}\left(\mathrm{CDCl}_{3}, 75 \mathrm{MHz}\right) 174.83(-\mathrm{CO}-$ $\mathrm{CH}(\mathrm{CH}-)-\mathrm{NH}-) ; 168.72$ (-NH-CO-CH $\left.2_{2}\right) ; 159.16$ (QC6); 144.67 (QC2); 144.05 (QC8); 135.05 (QC4); 134.58 (QC10); 129.66 (QC9); 121.65 (QC3); 96.50 (QC7); 91.43 (QC5); 76.02 and 76.01 $(-\mathrm{CO}-\mathrm{CH}(\mathrm{CH}-)-\mathrm{NH}-) ; 62.50\left(-\mathrm{C}\left(\mathrm{CH}_{3}\right)_{2}-\right) ; 54.98\left(\mathrm{CH}_{3}-\mathrm{O}-\right)$; 47.51 $\left(-\mathrm{NH}-\mathrm{CH}\left(\mathrm{CH}_{3}\right)-\right) ; 44.45\left(-\mathrm{CO}-\mathrm{CH}_{2}-\right) ; 39.19\left(-\left(\mathrm{CH}_{2}\right)_{2}-\mathrm{CH}_{2}-\right) ; 33.77$

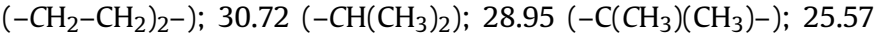
and $27.56\left(-\mathrm{C}\left(\mathrm{CH}_{3}\right)\left(\mathrm{CH}_{3}\right)-\right) ; 26.10$ and $26.05\left(-\mathrm{CH}_{2}-\mathrm{CH}_{2}-\mathrm{CH}_{2}-\right)$; $20.34\left(-\mathrm{NH}-\mathrm{CH}\left(\mathrm{CH}_{3}\right)-\right) ; 18.97$ and $18.95\left(-\mathrm{CH}\left(\mathrm{CH}_{3}\right)\left(\mathrm{CH}_{3}\right)\right) ; 16.67$ $\left(-\mathrm{CH}\left(\mathrm{CH}_{3}\right)\left(\mathrm{CH}_{3}\right)\right) . \quad \mathrm{C}_{25} \mathrm{H}_{37} \mathrm{~N}_{5} \mathrm{O}_{3} \quad\left(455.29 \mathrm{~g} \mathrm{~mol}^{-1}\right): \quad \mathrm{m} / \mathrm{z}$ $\left(\mathrm{MH}^{+}\right)=456.40 ; m / z\left(\mathrm{MNa}^{+}\right)=478.40$.

3-\{7-[(6-Methoxyquinolin-8-yl)amino]-3-aza-2-oxooctyl\}-5-isobutyl-2,2-dimethylimidazolidin-4-one, 5d. Yield 75\%; $\delta_{\mathrm{H}}\left(\mathrm{CDCl}_{3}\right.$,

Table 3

Effect of imidazolidin-4-ones $\mathbf{5 a}, \mathbf{5 b}, \mathbf{5 f}$ and primaquine on the sporogonic development of Plasmodium berghei ANKA in Anopheles stephensi mosquitoes. Counting of oocysts was carried out at day 10 post-feed.

\begin{tabular}{lllc}
\hline Compound & Dose, $\mu \mathrm{mol} \mathrm{kg}^{-1}$ & $\begin{array}{l}\text { Mean no. of oocysts } \\
\text { per mosquitoes, } \pm \text { SEM }^{\mathrm{a}}\end{array}$ & $\begin{array}{c}\text { \% Of infected } \\
\text { mosquitoes }\end{array}$ \\
\hline $\mathbf{1}$ & 10 & $12.2(2.9)$ & 14.1 \\
& 50 & $0.2(0.7)$ & 0.2 \\
$\mathbf{5 a}$ & 10 & $4.8(1.3)$ & 5.6 \\
& 50 & $3.8(1.3)$ & 4.4 \\
$\mathbf{5 b}$ & 10 & $81.3(3.5)^{\mathrm{b}}$ & 94.2 \\
& 50 & $2.1(0.2)$ & 2.4 \\
$\mathbf{5 f}$ & 10 & $1.3(0.2)$ & 1.5 \\
& 50 & $0.05(0.1)$ & 0.06 \\
Control & 0 & $86.7(4.0)$ & 100 \\
\hline
\end{tabular}

a Mean standard error.

b $P>0.05$ versus control, by Student's $t$ test.
$300 \mathrm{MHz}) 8.45(\mathrm{dd}, \mathrm{J}=4.09 \mathrm{~Hz}, \mathrm{~J}=1.31 \mathrm{~Hz} ; 1 \mathrm{H}, \mathrm{Q} 2) ; 7.86(\mathrm{dd}$, $\mathrm{J}=8.23 \mathrm{~Hz}, \mathrm{~J}=1.28 \mathrm{~Hz} ; 1 \mathrm{H}, \mathrm{Q} 4) ; 7.24(\mathrm{dd}, \mathrm{J}=8.27 \mathrm{~Hz}, \mathrm{~J}=4.26 \mathrm{~Hz}$; $1 \mathrm{H}, \mathrm{Q} 3) ; 6.69$ (bs; $\left.1 \mathrm{H},-\left(\mathrm{CH}_{2}\right)_{3}-\mathrm{NH}-\right) ; 6.27(\mathrm{~d}, \mathrm{~J}=2.37 \mathrm{~Hz} ; 1 \mathrm{H}, \mathrm{Q} 5$; $6.21(\mathrm{~d}, \mathrm{~J}=2.01 \mathrm{~Hz} ; 1 \mathrm{H}, \mathrm{Q} 7) ; 5.94$ and $5.93(\mathrm{~d}+\mathrm{d}, \mathrm{J}=7.85 \mathrm{~Hz}$, $\left.\mathrm{J}=7.91 \mathrm{~Hz} ; 1 \mathrm{H},-\mathrm{NH}-\mathrm{CH}\left(\mathrm{CH}_{3}\right)-\right) ; 3.86(\mathrm{~d}, \mathrm{~J}=15.62 \mathrm{~Hz} ; 1 \mathrm{H},-\mathrm{CO}-$ $\mathrm{CHH}-) ; 3.82\left(\mathrm{~s} ; 3 \mathrm{H}, \mathrm{CH}_{3}-\mathrm{O}-\right) ; 3.63$ and $3.61(\mathrm{~d}+\mathrm{d}, \mathrm{J}=15.47 \mathrm{~Hz}$, $\mathrm{J}=15.48 \mathrm{~Hz} ; 1 \mathrm{H},-\mathrm{CO}-\mathrm{CHH}-) ; 3.56-3.53\left(\mathrm{~m} ; 1 \mathrm{H},-\mathrm{CH}(\mathrm{NH}-)-\mathrm{CH}_{2}-\right)$; 3.48-3.45 (m; $\left.1 \mathrm{H},-\mathrm{NH}-\mathrm{CH}\left(\mathrm{CH}_{3}\right)-\right)$; 3.24-3.12 $\left(\mathrm{m} ; 2 \mathrm{H},-\left(\mathrm{CH}_{2}\right)_{2}-\right.$ $\left.\mathrm{CH}_{2}-\right) ; 1.77-1.68\left(\mathrm{~m} ; 3 \mathrm{H},-\mathrm{CH}_{2}-\mathrm{CH}\left(\mathrm{CH}_{3}\right)_{2}\right) ; 1.64-1.54\left(\mathrm{~m} ; 4 \mathrm{H},-\mathrm{CH}_{2}-\right.$ $\left.\mathrm{CH}_{2}-\mathrm{CH}_{2}-\right) ; 1.35$ and $1.34\left(\mathrm{~s}+\mathrm{s} ; 3 \mathrm{H},-\mathrm{C}\left(\mathrm{CH}_{3}\right)\left(\mathrm{CH}_{3}\right)-\right) ; 1.24$ and 1.23 $\left(\mathrm{s}+\mathrm{s} ; 3 \mathrm{H},-\mathrm{C}\left(\mathrm{CH}_{3}\right)\left(\mathrm{CH}_{3}\right)-\right) ; 1.23\left(\mathrm{~d}, \mathrm{~J}=5.55 \mathrm{~Hz} ; 3 \mathrm{H},-\mathrm{NH}-\mathrm{CH}\left(\mathrm{CH}_{3}\right)-\right.$ ); $0.88\left(\mathrm{~d}, \mathrm{~J}=6.23 \mathrm{~Hz} ; 3 \mathrm{H},-\mathrm{CH}\left(\mathrm{CH}_{3}\right)\left(\mathrm{CH}_{3}\right)\right) ; 0.86(\mathrm{~d}, \mathrm{~J}=6.13 \mathrm{~Hz} ; 3 \mathrm{H}$, $\left.-\mathrm{CH}\left(\mathrm{CH}_{3}\right)\left(\mathrm{CH}_{3}\right)\right) . \delta_{\mathrm{C}}\left(\mathrm{CDCl}_{3}, 75 \mathrm{MHz}\right) 176.50$ and $176.48(-\mathrm{CO}-$ $\left.\mathrm{CH}\left(\mathrm{CH}_{2}{ }^{-}\right)-\right) ; 168.70$ and 168.68 (-NH-CO-); 159.16 (QC6); 144.67 (QC2); 144.09 (QC8); 135.05 (QC4); 134.61 (QC10); 129.68 (QC9); 121.67 (QC3); 96.52 (QC7); 91.47 (QC5); $76.56\left(-\mathrm{CH}(\mathrm{NH}-)-\mathrm{CH}_{2-}\right)^{2}$; 56.07 and $56.06\left(-\mathrm{C}\left(\mathrm{CH}_{3}\right)_{2}-\right)$; $55.00\left(\mathrm{CH}_{3}-\mathrm{O}-\right) ; 47.53(-\mathrm{NH}-$ $\left.\mathrm{CH}\left(\mathrm{CH}_{3}\right)^{-}\right)$; 44.70 and $44.67\left(-\mathrm{CO}-\mathrm{CH}_{2}-\right) ; 41.25\left(-\mathrm{CH}_{2}-\mathrm{CH}\left(\mathrm{CH}_{3}\right)_{2}\right)$; 39.20 and $39.15\left(-\left(\mathrm{CH}_{2}\right)_{2}-\mathrm{CH}_{2}-\right)$; 33.79 and $\left.33.77\left(-\mathrm{CH}_{2}-\mathrm{CH}_{2}\right)_{2}-\right)$; $30.73\left(-\mathrm{CH}\left(\mathrm{CH}_{3}\right)_{2}\right) ; 27.51$ and $27.50\left(-\mathrm{C}\left(\mathrm{CH}_{3}\right)\left(\mathrm{CH}_{3}\right)-\right) ; 26.03$ and $26.01\left(-\mathrm{C}\left(\mathrm{CH}_{3}\right)\left(\mathrm{CH}_{3}\right)-\right) ; 24.98\left(-\mathrm{CH}_{2}-\mathrm{CH}_{2}-\mathrm{CH}_{2}-\right) ; 23.10$ and 23.08 $\left(-\mathrm{CH}\left(\mathrm{CH}_{3}\right)\left(\mathrm{CH}_{3}\right)\right) ; 21.30 \quad\left(-\mathrm{NH}-\mathrm{CH}\left(\mathrm{CH}_{3}\right)-\right) ; 20.38$ and 20.33

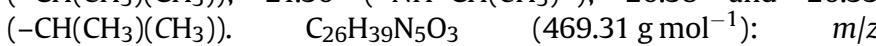
$\left(\mathrm{MH}^{+}\right)=470.33 ; \mathrm{m} / z\left(\mathrm{MNa}^{+}\right)=492.47$.

3-\{7-[(6-Methoxyquinolin-8-yl)amino]-3-aza-2-oxooctyl\}-5-benzyl2,2-dimethylimidazolidin-4-one, 5e. Yield 69\%; $\delta_{\mathrm{H}}\left(\mathrm{CDCl}_{3}, 300 \mathrm{MHz}\right)$ $8.52(\mathrm{dd}, \mathrm{J}=4.19 \mathrm{~Hz}, \mathrm{~J}=1.44 \mathrm{~Hz} ; 1 \mathrm{H}, \mathrm{Q} 2) ; 7.92$ and $7.91(\mathrm{dd}+\mathrm{dd}$, $\mathrm{J}=8.28 \mathrm{~Hz}, \mathrm{~J}=1.37 \mathrm{~Hz}$ and $\mathrm{J}=8.27 \mathrm{~Hz}, \mathrm{~J}=1.37 \mathrm{~Hz} ; 1 \mathrm{H}, \mathrm{Q} 4) ; 7.32-7.16$ (m; 6H, Q3, Ar2-6); 6.33 (d, J = 2.64 Hz; 1H, Q5); 6.27 (d, J=2.45 Hz; $1 \mathrm{H}, \mathrm{Q7}) ; 6.08-6.01\left(\mathrm{~m} ; 2 \mathrm{H},-\left(\mathrm{CH}_{2}\right)_{3}-\mathrm{NH}-\mathrm{CO}-,-\mathrm{NH}-\mathrm{CH}\left(\mathrm{CH}_{3}\right)-\mathrm{CH}_{2-}\right)$; 3.99 and $3.98(\mathrm{~d}+\mathrm{d}, \mathrm{J}=15.87 \mathrm{~Hz}$ and $\mathrm{J}=15.88 \mathrm{~Hz} ; 1 \mathrm{H},-\mathrm{NH}-\mathrm{CO}-$ $\mathrm{CHH}-)$; 3.88 (s; 3H, $\left.\mathrm{CH}_{3}-\mathrm{O}-\right)$; 3.86-3.83 (m; $\left.1 \mathrm{H},-\mathrm{CO}-\mathrm{CH}\left(\mathrm{CH}_{2}\right)-\right)$; 3.61 $\left(\mathrm{m} ; 1 \mathrm{H},-\mathrm{NH}-\mathrm{CH}\left(\mathrm{CH}_{3}\right)-\mathrm{CH}_{2}-\right) ; 3.52$ and $3.51(\mathrm{~d}+\mathrm{d}, \mathrm{J}=15.88 \mathrm{~Hz}$, $\mathrm{J}=15.89 \mathrm{~Hz} ; 1 \mathrm{H},-\mathrm{NH}-\mathrm{CO}-\mathrm{CHH}-) ; 3.19-3.00\left(\mathrm{~m} ; 4 \mathrm{H},-\left(\mathrm{CH}_{2}\right)_{2}-\mathrm{CH}_{2}-\right.$, - $\left.\mathrm{CO}-\mathrm{CH}\left(\mathrm{CH}_{2}\right)-\right) ; 1.98-1.87$ (m; $\left.1 \mathrm{H},-\mathrm{CO}-\mathrm{CH}-\mathrm{NH}-\right) ; 1.67-1.51(\mathrm{~m} ; 4 \mathrm{H}$, $\left.-\mathrm{CH}_{2}-\mathrm{CH}_{2}-\mathrm{CH}_{2}-\right) ; 1.31$ and $1.30\left(\mathrm{~s}+\mathrm{s} ; 3 \mathrm{H},-\mathrm{N}-\mathrm{C}\left(\mathrm{CH}_{3}\right)\left(\mathrm{CH}_{3}\right)-\mathrm{NH}-\right)$; 1.29 and $1.28\left(\mathrm{~s}+\mathrm{s}\right.$; $\left.3 \mathrm{H},-\mathrm{N}-\mathrm{C}\left(\mathrm{CH}_{3}\right)\left(\mathrm{CH}_{3}\right)-\mathrm{NH}-\right) ; 1.12(\mathrm{~d}, \mathrm{~J}=5.92 \mathrm{~Hz}$; $\left.3 \mathrm{H},-\mathrm{NH}-\mathrm{C}\left(\mathrm{CH}_{3}\right)-\right) . \delta_{\mathrm{C}}\left(\mathrm{CDCl}_{3}, 75 \mathrm{MHz}\right) 174.85(-\mathrm{N}-\mathrm{CO}-\mathrm{CH}-) ; 168.17$ (-NH-CO- $\left.\mathrm{CH}_{2}-\right)$; $159.42-91.73$ ( $\left.\mathrm{ArC}\right)$; $67.96\left(-\mathrm{CO}-\mathrm{CH}\left(\mathrm{CH}_{2}\right)-\mathrm{NH}-\right)$; $58.72\left(-\mathrm{N}-\mathrm{C}\left(\mathrm{CH}_{3}\right)_{2}-\mathrm{NH}-\right)$; $55.20\left(\mathrm{CH}_{3}-\mathrm{O}-\right) ; 47.71\left(-\mathrm{NH}-\mathrm{CH}\left(\mathrm{CH}_{3}\right)-\right.$ $\left.\mathrm{CH}_{2-}\right)$; $44.64\left(-\mathrm{NH}-\mathrm{CO}-\mathrm{CH}_{2}-\mathrm{N}-\right)$; $39.36\left(-\left(\mathrm{CH}_{2}\right)_{2}-\mathrm{CH}_{2}-\right)$; 36.33 (-CO$\left.\mathrm{CH}\left(\mathrm{CH}_{2}\right)-\right) ; 33.96\left(-\mathrm{CH}_{2}-\left(\mathrm{CH}_{2}\right)_{2}-\right) ; 27.32\left(-\mathrm{N}-\mathrm{C}\left(\mathrm{CH}_{3}\right)-\mathrm{CH}_{3}-\mathrm{NH}-\right)$; $26.31\left(-\mathrm{N}-\mathrm{C}\left(\mathrm{CH}_{3}\right)-\mathrm{CH}_{3}-\mathrm{NH}-\right) ; 25.75\left(-\mathrm{CH}_{2}-\mathrm{CH}_{2}-\mathrm{CH}_{2}-\right) ; 20.58(-\mathrm{NH}-$ $\left.\mathrm{CH}\left(\mathrm{CH}_{3}\right)-\mathrm{CH}_{2}-\right) . \quad \mathrm{C}_{29} \mathrm{H}_{37} \mathrm{~N}_{5} \mathrm{O}_{3} \quad\left(503.2896 \mathrm{~g} \mathrm{~mol}^{-1}\right): \mathrm{m} / \mathrm{z} \quad\left(\mathrm{MH}^{+}\right)=$ 504.2633.

3-\{7-[(6-Methoxyquinolin-8-yl)amino]-3-aza-1-methyl-2-oxooctyl\}-2,2,5-trimethylimidazolidin-4-one, 5f. Yield 38\%; $\delta_{\mathrm{H}}\left(\mathrm{CDCl}_{3}\right.$, $300 \mathrm{MHz}) 8.52(\mathrm{dd}, \mathrm{J}=4.22 \mathrm{~Hz}, \mathrm{~J}=1.76 \mathrm{~Hz} ; 1 \mathrm{H}, \mathrm{Q} 2) ; 7.91$ (dd, $\mathrm{J}=8.27 \mathrm{~Hz}, \mathrm{~J}=1.64 \mathrm{~Hz} ; 1 \mathrm{H}, \mathrm{Q} 4) ; 7.71\left(\mathrm{~m} ; 1 \mathrm{H},-\left(\mathrm{CH}_{2}\right)_{3}-\mathrm{NH}-\mathrm{CO}-\right)$; 7.30 and $7.29(\mathrm{dd}+\mathrm{dd}, \mathrm{J}=8.30 \mathrm{~Hz}, \mathrm{~J}=4.16 \mathrm{~Hz}$ and $\mathrm{J}=8.27 \mathrm{~Hz}$, $\mathrm{J}=4.20 \mathrm{~Hz} ; 1 \mathrm{H}, \mathrm{Q} 3) ; 6.33$ and $6.27(\mathrm{~d}+\mathrm{d}, \mathrm{J}=2.29 \mathrm{~Hz}$ and $\mathrm{J}=2.42 \mathrm{~Hz} ; 2 \mathrm{H}, \mathrm{Q} 5, \mathrm{Q} 7) ; 6.00\left(\mathrm{~m} ; 1 \mathrm{H},-\mathrm{NH}-\mathrm{CH}\left(\mathrm{CH}_{3}\right)-\right) ; 3.88(\mathrm{~s}$; $\left.3 \mathrm{H}, \mathrm{CH}_{3}-\mathrm{O}-\right)$; 3.78-3.72 (m; $\left.1 \mathrm{H},-\mathrm{CO}-\mathrm{CH}\left(\mathrm{CH}_{3}\right)-\right) ; 3.64-3.49(\mathrm{~m}$; $\left.2 \mathrm{H},-\mathrm{CO}-\mathrm{CH}\left(\mathrm{CH}_{3}\right)-\mathrm{NH}-,-\mathrm{NH}-\mathrm{CH}\left(\mathrm{CH}_{3}\right)-\mathrm{CH}_{2}-\right) ; 3.38-3.12(\mathrm{~m} ; 2 \mathrm{H}$, $\left.-\mathrm{CH}_{2}-\mathrm{CH}_{2}-\mathrm{CH}_{2}-\right) ; 1.72-1.61\left(\mathrm{~m} ; 8 \mathrm{H},-\mathrm{CH}_{2}-\mathrm{CH}_{2}-\mathrm{CH}_{2}-\right.$, $-\mathrm{CO}-$ $\left.\mathrm{CH}\left(\mathrm{CH}_{3}\right)-\mathrm{NH}-, \quad-\mathrm{CO}-\mathrm{CH}\left(\mathrm{CH}_{3}\right)-\mathrm{N}-\right) ; \quad 1.40-1.26 \quad(\mathrm{~m} ; \quad 12 \mathrm{H}, \quad-\mathrm{N}-$ $\left.\mathrm{C}\left(\mathrm{CH}_{3}\right)_{2}-\mathrm{NH}-\mathrm{CH}\left(\mathrm{CH}_{3}\right)-\mathrm{CO}-, \quad-\mathrm{NH}-\mathrm{CH}\left(\mathrm{CH}_{3}\right)-\mathrm{CH}_{2}-\right) . \quad \delta_{\mathrm{C}} \quad\left(\mathrm{CDCl}_{3}\right.$, $75 \mathrm{MHz}) \quad 176.85$ (-N-CO-CH(CH$\left.)_{3}-\mathrm{NH}-\right) ; 172.34$ (-NH-CO$\left.\mathrm{CH}\left(\mathrm{CH}_{3}\right)-\right) ; 159.40-91.67(\mathrm{ArC}) ; 55.64\left(-\mathrm{N}-\mathrm{C}\left(\mathrm{CH}_{3}\right)_{2}-\mathrm{NH}-\right) ; 55.22$ $\left(\mathrm{CH}_{3}-\mathrm{O}-\right) ; 53.78\left(-\mathrm{CO}-\mathrm{CH}\left(\mathrm{CH}_{3}\right)-\mathrm{NH}-\right) ; 50.57\left(-\mathrm{NH}-\mathrm{CO}-\mathrm{CH}\left(\mathrm{CH}_{3}\right)-\right.$ ); $47.75\left(-\mathrm{NH}-\mathrm{CH}\left(\mathrm{CH}_{3}\right)-\mathrm{CH}_{2}-\right)$; $39.34\left(-\mathrm{CH}_{2}-\mathrm{CH}_{2}-\mathrm{CH}_{2}-\right) ; 33.97$ $\left(-\mathrm{CH}_{2}-\mathrm{CH}_{2}-\mathrm{CH}_{2}-\right) ; 30.36\left(-\mathrm{N}-\mathrm{C}\left(\mathrm{CH}_{3}\right)_{2}-\mathrm{NH}-\right) ; 26.17\left(-\mathrm{CH}_{2}-\mathrm{CH}_{2}-\right.$ $\left.\mathrm{CH}_{2-}\right)$; $20.59\left(-\mathrm{NH}-\mathrm{CH}\left(\mathrm{CH}_{3}\right)-\mathrm{CH}_{2}-\right) ; 16.84\left(-\mathrm{CO}-\mathrm{CH}\left(\mathrm{CH}_{3}\right)-\mathrm{NH}-\right)$; $15.54\left(-\mathrm{NH}-\mathrm{CO}-\mathrm{CH}\left(\mathrm{CH}_{3}\right)-\right) . \mathrm{C}_{24} \mathrm{H}_{35} \mathrm{~N}_{5} \mathrm{O}_{3}\left(441.2740 \mathrm{~g} \mathrm{~mol}^{-1}\right): \mathrm{m} / \mathrm{z}$ $\left(\mathrm{MH}^{+}\right)=442.2897$. 
3-\{7-[(6-Methoxyquinolin-8-yl)amino]-3-aza-1-methyl-2-oxooctyl]-5-[(2-methylthio)ethyl]-2,2-dimethylimidazolidin-4-one, $\quad \mathbf{5 g}$. Yield 62\%; $\delta_{\mathrm{H}}\left(\mathrm{CDCl}_{3}, 300 \mathrm{MHz}\right) 8.50(4)$ and $8.50(9)(\mathrm{dd}+\mathrm{dd}$, $\mathrm{J}=4.21 \mathrm{~Hz}, \mathrm{~J}=1.41 \mathrm{~Hz}$ and $\mathrm{J}=4.16 \mathrm{~Hz}, \mathrm{~J}=1.41 \mathrm{~Hz} ; 1 \mathrm{H}, \mathrm{Q} 2) ; 7.89$ $(\mathrm{dd}, \mathrm{J}=8.26 \mathrm{~Hz}, \mathrm{~J}=1.60 \mathrm{~Hz}) ; 1 \mathrm{H}, \mathrm{Q} 4) ; 7.66-7.58\left(\mathrm{~m} ; 1 \mathrm{H},-\left(\mathrm{CH}_{2}\right)_{3}-\right.$ $\mathrm{NH}-$ ); 7.28 (dd, J = 8.27 Hz, J = 4.20 Hz; $1 \mathrm{H}, \mathrm{Q} 3) ; 6.31(\mathrm{~d}, \mathrm{~J}=2.42 \mathrm{~Hz}$; $1 \mathrm{H}, \mathrm{Q} 5) ; 6.25$ and $6.24(\mathrm{~d}+\mathrm{d}, \mathrm{J}=3.01 \mathrm{~Hz}$ and $\mathrm{J}=2.82 \mathrm{~Hz} ; 1 \mathrm{H}, \mathrm{Q} 7)$; $5.98\left(\mathrm{~d}, \mathrm{~J}=6.91 \mathrm{~Hz} ; 1 \mathrm{H},-\mathrm{NH}-\mathrm{CH}\left(\mathrm{CH}_{3}\right)-\mathrm{CH}_{2}-\right) ; 3.86(5)$ and $3.86(1)$ $\left(\mathrm{s}+\mathrm{s} ; 3 \mathrm{H}, \mathrm{CH}_{3}-\mathrm{O}-\right)$; 3.76-3.72 (m; $\left.1 \mathrm{H},-\mathrm{CO}-\mathrm{CH}\left(\mathrm{CH}_{3}\right)-\right) ; 3.68-3.58$ (m; $\left.2 \mathrm{H},-\mathrm{NH}-\mathrm{CH}\left(\mathrm{CH}_{3}\right)-\mathrm{CH}_{2}-,-\mathrm{CO}-\mathrm{CH}\left(\mathrm{CH}_{2}-\mathrm{Ph}\right)-\right)$; 3.36-3.26 (m; $\left.1 \mathrm{H},-\left(\mathrm{CH}_{2}\right)_{2}-\mathrm{CHH}-\right) ; 3.21-3.10\left(\mathrm{~m} ; 1 \mathrm{H},-\left(\mathrm{CH}_{2}\right)_{2}-\mathrm{CHH}-\right) ; 2.61-2.51$ (m; $2 \mathrm{H},-\mathrm{CH}_{2}-\mathrm{CH}_{2}-\mathrm{S}-$ ); 2.04 and 2.01 ( $\left.\mathrm{s}+\mathrm{s} ; 3 \mathrm{H},-\mathrm{CH}_{2}-\mathrm{S}-\mathrm{CH}_{3}\right) ; 1.98$ (bs; $\left.1 \mathrm{H},-\mathrm{CO}-\mathrm{CH}\left(\mathrm{CH}_{2}-\right)-\mathrm{NH}-\right)$; $1.85-1.65\left(\mathrm{~m} ; 4 \mathrm{H},-\mathrm{CH}_{2}-\mathrm{CH}_{2}-\mathrm{CH}_{2}-\right.$ ); 1.63 and $1.60\left(\mathrm{~s}+\mathrm{s} ; 6 \mathrm{H},-\mathrm{N}-\mathrm{C}\left(\mathrm{CH}_{3}\right)_{2}-\mathrm{NH}-\right) ; 1.37$ and 1.31 (bs + bs; $\left.3 \mathrm{H}, \quad-\mathrm{CO}-\mathrm{CH}\left(\mathrm{CH}_{3}\right)-\right) ; 1.28(1)$ and $1.27(8)(\mathrm{d}+\mathrm{d}, \mathrm{J}=6.32 \mathrm{~Hz}$, $\left.\mathrm{J}=6.34 \mathrm{~Hz} ; 3 \mathrm{H},-\mathrm{NH}-\mathrm{CH}\left(\mathrm{CH}_{3}\right)-\mathrm{CH}_{2}-\right) . \delta_{\mathrm{C}}\left(\mathrm{CDCl}_{3}, 75 \mathrm{MHz}\right) 176.13$ and $176.07\left(-\mathrm{CO}-\mathrm{CH}\left(\mathrm{CH}_{2}{ }^{-}\right)-\mathrm{NH}-\right)$; 172.59 and 172.25 (-NH-CO$\mathrm{CH}\left(\mathrm{CH}_{3}\right)-$ ); 159.81 (QC6); 145.33 (QC2); 144.73 (QC8); 135.76 and 135.73 (QC4); 135.19 (QC10); 130.32 and 130.30 (QC9); 122.28 (QC3); 97.12 and 97.07 (QC7); 92.08 (QC5); $78.21\left(-\mathrm{CH}\left(\mathrm{CH}_{2}-\right)-\mathrm{NH}-\right.$ ); 57.04 and $56.96\left(-\mathrm{N}-\mathrm{C}\left(\mathrm{CH}_{3}\right)_{2}-\mathrm{NH}-\right)$; 55.79 and $55.72(-\mathrm{CO}-$ $\left.\mathrm{CH}\left(\mathrm{CH}_{3}\right)-\right)$; 55.64 and $55.63\left(\mathrm{CH}_{3}-\mathrm{O}-\right) ; 48.20$ and $48.16(-\mathrm{NH}-$ $\left.\mathrm{CH}\left(\mathrm{CH}_{3}\right)-\mathrm{CH}_{2}-\right)$; 39.77 and $39.72\left(-\left(\mathrm{CH}_{2}\right)_{2}-\mathrm{CH}_{2-}\right)$; $34.39\left(-\mathrm{CH}_{2-}\right.$ $\left.\left(\mathrm{CH}_{2}\right)_{2}-\right) ; 31.02$ and $31.01\left(-\mathrm{CH}_{2}-\mathrm{CH}_{2}-\mathrm{S}-\right) ; 30.79$ and $30.76\left(-\mathrm{CH}_{2-}\right.$ $\left.\mathrm{CH}_{2}-\mathrm{S}-\right) ; 28.80$ and $28.73\left(-\mathrm{C}\left(\mathrm{CH}_{3}\right)\left(\mathrm{CH}_{3}\right)-\mathrm{NH}-\right) ; 26.66$ and $26.64\left(-\mathrm{CH}_{2}-\mathrm{CH}_{2}-\mathrm{CH}_{2}-\right)$; 26.11 and $26.03\left(-\mathrm{C}\left(\mathrm{CH}_{3}\right)\left(\mathrm{CH}_{3}\right)-\mathrm{NH}-\right)$; 20.95 and $20.91\left(-\mathrm{NH}-\mathrm{CH}\left(\mathrm{CH}_{3}\right)-\mathrm{CH}_{2}-\right) ; 16.02\left(-\mathrm{S}-\mathrm{CH}_{3}\right) ; 15.64$ and $15.62\left(-\mathrm{CO}-\mathrm{CH}\left(\mathrm{CH}_{3}\right)-\right) \cdot \mathrm{C}_{26} \mathrm{H}_{39} \mathrm{~N}_{5} \mathrm{O}_{3} \mathrm{~S} \quad\left(501.28 \mathrm{~g} \mathrm{~mol}^{-1}\right): \mathrm{m} / \mathrm{z}$ $\left(\mathrm{MNa}^{+}\right)=524.93$.

3-\{7-[(6-Methoxyquinolin-8-yl)amino]-3-aza-1-isobutyl-2-oxooctyl\}2,2-dimethylimidazolidin-4-one, $\mathbf{5 h}$. Yield $21 \% ; \delta_{\mathrm{H}}\left(\mathrm{CDCl}_{3}, 300 \mathrm{MHz}\right)$ 8.54-8.52 (m; 1H, Q2); 7.92 (d, J = 8.12 Hz; 1H, Q4); 7.32-7.28 (m; 1H, Q3); 6.33 (d, J=1.69 Hz; 1H, Q5); 6.27 (d, J=1.58 Hz; 1H, Q7); 6.02$5.92\left(\mathrm{~m} ; 1 \mathrm{H},-\mathrm{NH}-\mathrm{CH}\left(\mathrm{CH}_{3}\right)-\mathrm{CH}_{2}-\right) ; 4.42-4.30\left(\mathrm{~m} ; 1 \mathrm{H},-\left(\mathrm{CH}_{2}\right)_{3}-\mathrm{NH}-\right)$; 3.89 (s; 3H, $\left.\mathrm{CH}_{3}-\mathrm{O}-\right)$; 3.89-3.86 (m; $\left.1 \mathrm{H},-\mathrm{CH}(\mathrm{CO}-)-\mathrm{CH}_{2}-\right) ; 3.66-3.53$ (m; $\left.2 \mathrm{H},-\mathrm{NH}-\mathrm{CH}\left(\mathrm{CH}_{3}\right)-\mathrm{CH}_{2}-,-\mathrm{CH}_{2}-\mathrm{CH}\left(\mathrm{CH}_{3}\right)_{2}\right) ; 3.30-3.20(\mathrm{~m} ; 2 \mathrm{H}$, $\left.-\left(\mathrm{CH}_{2}\right)_{2}-\mathrm{CH}_{2}-\right)$; $1.71-1.54\left(\mathrm{~m} ; 9 \mathrm{H},-\mathrm{CH}_{2}-\mathrm{CH}_{2}-\mathrm{CH}_{2}-,-\mathrm{CO}-\mathrm{CH}_{2}-\mathrm{NH}-\right.$, $\left.-\mathrm{CH}_{2}-\mathrm{CH}\left(\mathrm{CH}_{3}\right)_{2}\right) ; 1.30-1.13\left(\mathrm{~m} ; 9 \mathrm{H},-\mathrm{N}(\mathrm{CO}-)-\mathrm{C}\left(\mathrm{CH}_{3}\right)_{2},-\mathrm{NH}-\mathrm{CH}\left(\mathrm{CH}_{3}\right)-\right.$ $\left.\mathrm{CH}_{2}-\right)$; 0.94-0.81 (m; 6H, $\left.-\mathrm{CH}_{2}-\mathrm{CH}\left(\mathrm{CH}_{3}\right)_{2}\right) . \delta_{\mathrm{C}}\left(\mathrm{CDCl}_{3}, 75 \mathrm{MHz}\right) 170.67$ $\left(-\mathrm{CH}_{2}-\mathrm{NH}-\mathrm{CO}-\right) ; 166.40$ (-CO-CH$\left.{ }_{2}-\mathrm{NH}-\right) ; 159.81$ (QC6); 145.32 (QC2); 144.74 (QC8); 135.77 and 135.72 (QC4); 135.29 and 135.25 (QC10); 130.34 (QC9); 122.31 (QC3); 97.26 (QC7); 92.18 (QC5); 67.20 $\left(-\mathrm{N}(\mathrm{CO}-)-\mathrm{C}\left(\mathrm{CH}_{3}\right)_{2}-\right) ; 55.63\left(\mathrm{CH}_{3}-\mathrm{O}-\right) ; 52.73\left(-\mathrm{CO}-\mathrm{CH}_{2}-\mathrm{NH}-\right) ; 48.25$ $\left(-\mathrm{NH}-\mathrm{CH}\left(\mathrm{CH}_{3}\right)-\mathrm{CH}_{2}-\right)$; $48.18\left(-\mathrm{CH}(\mathrm{CO}-)\left(\mathrm{CH}_{2}-\right)-\right)$; $39.94\left(-\left(\mathrm{CH}_{2}\right)_{2-}\right.$ $\left.\mathrm{CH}_{2}-\right)$; $39.80\left(-\mathrm{CH}_{2}-\mathrm{CH}\left(\mathrm{CH}_{3}\right)_{2}\right) ; 34.34\left(-\mathrm{CH}_{2}-\left(\mathrm{CH}_{2}\right)_{2}-\right) ; 30.72$ and $30.64\left(-\mathrm{C}\left(\mathrm{CH}_{3}\right)\left(\mathrm{CH}_{3}\right)-\mathrm{NH}-\right)$; 30.12 and $30.08\left(-\mathrm{C}\left(\mathrm{CH}_{3}\right)\left(\mathrm{CH}_{3}\right)-\mathrm{NH}-\right)$; $25.34\left(-\mathrm{CH}_{2}-\mathrm{CH}_{2}-\mathrm{CH}_{2-}\right) ; 25.19\left(-\mathrm{CH}_{2}-\mathrm{CH}\left(\mathrm{CH}_{3}\right)_{2}\right) ; 21.93\left(-\mathrm{CH}_{2-}\right.$ $\left.\mathrm{CH}\left(\mathrm{CH}_{3}\right)\left(\mathrm{CH}_{3}\right)\right) ; 21.71\left(-\mathrm{CH}_{2}-\mathrm{CH}\left(\mathrm{CH}_{3}\right)\left(\mathrm{CH}_{3}\right) ; 20.96\left(-\mathrm{NH}-\mathrm{CH}\left(\mathrm{CH}_{3}\right)-\right.\right.$ $\left.\mathrm{CH}_{2}-\right) . \mathrm{C}_{26} \mathrm{H}_{39} \mathrm{~N}_{5} \mathrm{O}_{3}\left(469.3053 \mathrm{~g} \mathrm{~mol}^{-1}\right): \mathrm{m} / z\left(\mathrm{MH}^{+}\right)=470.2928$.

3-\{7-[(6-Methoxyquinolin-8-yl)amino $]-3-a z a-2$-oxooctyl $\}-1,4-$ diazaspiro[4.5]decan-2-one, 5i. Yield 73\%; $\delta_{\mathrm{H}}\left(\mathrm{CDCl}_{3}, 300 \mathrm{MHz}\right) 8.53$ (dd, J=4.19 Hz, J=1.72 Hz; $1 \mathrm{H}, \quad \mathrm{Q} 2) ; 7.92$ (dd, J=8.28 Hz; $\mathrm{J}=1.59 \mathrm{~Hz} ; 1 \mathrm{H}, \mathrm{Q} 4) ; 7.31(\mathrm{dd}, \mathrm{J}=8.17 \mathrm{~Hz}, \mathrm{~J}=4.24 \mathrm{~Hz} ; 1 \mathrm{H}, \mathrm{Q} 3) ; 6.61$ $\left(\mathrm{t}, \mathrm{J}=5.47 \mathrm{~Hz} ; 1 \mathrm{H},-\left(\mathrm{CH}_{2}\right)_{3}-\mathrm{NH}-\right) ; 6.34(\mathrm{~d}, \mathrm{~J}=2.47 \mathrm{~Hz} ; 1 \mathrm{H}, \mathrm{Q} 5) ; 6.26$ $(\mathrm{d}, \mathrm{J}=2.44 \mathrm{~Hz} ; 1 \mathrm{H}, \mathrm{Q} 7) ; 5.99\left(\mathrm{~d}, \mathrm{~J}=8.00 \mathrm{~Hz} ; 1 \mathrm{H},-\mathrm{NH}-\mathrm{CH}\left(\mathrm{CH}_{3}\right)-\right.$ $\mathrm{CH}_{2}-$ ); 3.89 (s; $\left.3 \mathrm{H}, \mathrm{CH}_{3}-\mathrm{O}-\right)$; 3.78(1) and 3.77(5) (s+s; $2 \mathrm{H},-\mathrm{NH}-$ $\mathrm{CO}-\mathrm{CHH}-\mathrm{N}-)$; $3.66-3.56\left(\mathrm{~m} ; 1 \mathrm{H},-\mathrm{NH}-\mathrm{CH}\left(\mathrm{CH}_{3}\right)-\mathrm{CH}_{2}-\right) ; 3.42(\mathrm{~d}$; $\left.\mathrm{J}=1.06 \mathrm{~Hz} ; 2 \mathrm{H},-\mathrm{CO}-\mathrm{CH}_{2}-\mathrm{NH}-\right)$ 3.30-3.21 (m; $2 \mathrm{H},-\left(\mathrm{CH}_{2}\right)_{2}-\mathrm{CH}_{2-}$ $\mathrm{NH}-) ; 2.34\left(\mathrm{t}, \mathrm{J}=6.52 \mathrm{~Hz} ; 3 \mathrm{H},-\mathrm{CO}-\mathrm{CH}_{2}-\mathrm{NH}-\right) ; 1.88-1.58(\mathrm{~m} ; 14 \mathrm{H}$, $\left.-\mathrm{CH}_{2}-\mathrm{CH}_{2}-\mathrm{CH}_{2}-\mathrm{NH}-,-\left(\mathrm{CH}_{2}\right)_{5}-\right) ; 1.29(\mathrm{~d}, \mathrm{~J}=6.41 \mathrm{~Hz} ; 3 \mathrm{H},-\mathrm{NH}-$ $\left.\mathrm{CH}\left(\mathrm{CH}_{3}\right)-\mathrm{CH}_{2}-\right) . \quad \delta_{\mathrm{C}}\left(\mathrm{CDCl}_{3}, 75 \mathrm{MHz}\right) 175.44 \quad\left(-\mathrm{NH}-\mathrm{CO}-\mathrm{CH}_{2}-\right)$; 169.48 (-CO- $\left.\mathrm{CH}_{2}-\mathrm{NH}-\right)$; 159.81-92.11 ( $\left.\mathrm{ArC}\right) ; 81.08$ (-N-C-Ar); $55.64\left(\mathrm{CH}_{3}-\mathrm{O}-\right) ; 48.15\left(-\mathrm{NH}-\mathrm{CH}\left(\mathrm{CH}_{3}\right)-\mathrm{CH}_{2}-\right) ; 45.06\left(-\mathrm{CO}-\mathrm{CH}_{2}-\right.$ $\mathrm{NH}-)$; 42.40 (-NH-CO-CH$-\mathrm{N}-)$; $39.76\left(-\left(\mathrm{CH}_{2}\right)_{2}-\mathrm{CH}_{2}-\mathrm{NH}-\right) ; 34.96$ $\left(-\mathrm{CH}_{2}-\right)$; $34.80\left(-\mathrm{CH}_{2}-\right) ; 34.65\left(-\mathrm{CH}_{2}-\left(\mathrm{CH}_{2}\right)_{2}-\mathrm{NH}-\right) ; 27.44\left(-\mathrm{CH}_{2}\right)$;
$26.59\left(-\mathrm{CH}_{2}-\mathrm{CH}_{2}-\mathrm{CH}_{2}-\mathrm{NH}-\right)$; $25.05\left(-\mathrm{NH}-\mathrm{CH}\left(\mathrm{CH}_{3}\right)-\mathrm{CH}_{2}-\right) ; 22.85$ $\left(-\mathrm{CH}_{2}-\right) ; 20.96\left(-\mathrm{CH}_{2}-\right) . \mathrm{C}_{25} \mathrm{H}_{35} \mathrm{~N}_{5} \mathrm{O}_{3} \quad\left(453.2740 \mathrm{~g} \mathrm{~mol}^{-1}\right): \mathrm{m} / \mathrm{z}$ $\left(\mathrm{MH}^{+}\right)=454.3169 ; m / z\left(\mathrm{MNa}^{+}\right)=476.2732$.

3-\{7-[(6-Methoxyquinolin-8-yl)amino]-3-aza-1-methyl-2-oxooctyl\}-1,4-diazaspiro[4.5]decan-2-one, 5j. Yield 37\%; $\delta_{\mathrm{H}}\left(\mathrm{CDCl}_{3}\right.$, $300 \mathrm{MHz}$ ) 8.52 (dd, J=4.16 Hz, J=1.42 Hz; 1H, Q2); 7.92 (dd, $\mathrm{J}=8.26 \mathrm{~Hz}, \mathrm{~J}=1.57 \mathrm{~Hz} ; 1 \mathrm{H}, \mathrm{Q} 4) ; 7.30(\mathrm{dd}, \mathrm{J}=8.21 \mathrm{~Hz}, \mathrm{~J}=4.20 \mathrm{~Hz}$; $1 \mathrm{H}, \mathrm{Q} 3) ; 6.72-6.59\left(\mathrm{~m} ; 1 \mathrm{H},-\left(\mathrm{CH}_{2}\right)_{3}-\mathrm{NH}-\right) ; 6.33(\mathrm{~d}, \mathrm{~J}=2.40 \mathrm{~Hz} ; 1 \mathrm{H}$, Q5); $6.26(\mathrm{~d}, \mathrm{~J}=2.35 \mathrm{~Hz} ; 1 \mathrm{H}, \mathrm{Q} 7) ; 5.99$ (bs; $1 \mathrm{H},-\mathrm{NH}-\mathrm{CH}\left(\mathrm{CH}_{3}\right)-\mathrm{CH}_{2}-$ ); 3.89 (bs; $\left.4 \mathrm{H}, \mathrm{CH}_{3}-\mathrm{O}-,-\mathrm{CO}-\mathrm{CH}\left(\mathrm{CH}_{3}\right)-\right)$; 3.63-3.60 (m; $1 \mathrm{H},-\mathrm{NH}-$ $\left.\mathrm{CH}\left(\mathrm{CH}_{3}\right)-\mathrm{CH}_{2}-\right)$; 3.53-3.36 (m; $\left.2 \mathrm{H},-\mathrm{CO}-\mathrm{CH}_{2}-\mathrm{NH}-\right) ; 3.30-3.13(\mathrm{~m}$; $\left.2 \mathrm{H},-\left(\mathrm{CH}_{2}\right)-\mathrm{CH}_{2}-\mathrm{NH}-\right) ; 2.34\left(\mathrm{t}, \mathrm{J}=6.47 \mathrm{~Hz} ; 1 \mathrm{H},-\mathrm{CO}-\mathrm{CH}_{2}-\mathrm{NH}-\right)$; $1.90-1.79\left(\mathrm{~m} ; 4 \mathrm{H},-\mathrm{CH}_{2}-\mathrm{CH}_{2}-\mathrm{CH}_{2}-\mathrm{NH}-\right) ; 1.72-1.61(\mathrm{~m} ; 10 \mathrm{H}$, $\left.-\left(\mathrm{CH}_{2}\right)_{5}-\right) ; 1.31$ (d, J=6.97 Hz; 3H, $\left.-\mathrm{CO}-\mathrm{CH}\left(\mathrm{CH}_{3}\right)-\right) ; 1.28$ (d, $\left.\mathrm{J}=6.38 \mathrm{~Hz} ; 3 \mathrm{H},-\mathrm{NH}-\mathrm{CH}\left(\mathrm{CH}_{3}\right)-\right) . \delta_{\mathrm{C}}\left(\mathrm{CDCl}_{3}, 75 \mathrm{MHz}\right) 177.49(-\mathrm{NH}-$ $\left.\mathrm{CO}-\mathrm{CH}\left(\mathrm{CH}_{3}\right)-\right)$; 169.68 (-CO-CH$\left.-\mathrm{NH}-\right)$; 159.84-92.10 ( $\left.\mathrm{ArC}\right) ; 79.12$ $(-\mathrm{C}-)$; $55.63\left(\mathrm{CH}_{3}-\mathrm{O}-\right)$; $53.80\left(-\mathrm{CO}-\mathrm{CH}_{2}-\mathrm{NH}-\right) ; 48.81$ (-CO$\left.\left.\mathrm{CH}\left(\mathrm{CH}_{3}\right)-\right) ; 48.14\left(-\mathrm{NH}-\mathrm{CH}\left(\mathrm{CH}_{3}\right)-\mathrm{CH}_{2}-\right) ; 39.71\left(-\mathrm{CH}_{2}\right)_{2}-\mathrm{CH}_{2}-\mathrm{NH}-\right)$; 37.66 and $36.12\left(-\mathrm{CH}_{2}-\right)$; $33.53\left(-\mathrm{CH}_{2}-\left(\mathrm{CH}_{2}\right)_{2}-\mathrm{NH}-\right) ; 27.44\left(-\mathrm{CH}_{2}\right)_{2-}$ )$; 25.02\left(-\mathrm{CH}_{2}-\mathrm{CH}_{2}-\mathrm{CH}_{2}-\mathrm{NH}-\right) ; 23.23$ and $22.53\left(-\mathrm{CH}_{2}-\right) ; 21.00$ $\left(-\mathrm{NH}-\mathrm{CH}\left(\mathrm{CH}_{3}\right)-\mathrm{CH}_{2}-\right) ; \quad 18.14 \quad\left(-\mathrm{CO}-\mathrm{CH}\left(\mathrm{CH}_{3}\right)-\right) . \quad \mathrm{C}_{26} \mathrm{H}_{37} \mathrm{~N}_{5} \mathrm{O}_{3}$ $\left(467.2896 \mathrm{~g} \mathrm{~mol}^{-1}\right): \quad m / z \quad\left(\mathrm{MH}^{+}\right)=468.2452 ; \quad m / z \quad\left(\mathrm{MNa}^{+}\right)=$ 490.2249 .

3-\{7-[(6-Methoxyquinolin-8-yl)amino]-3-aza-1-isobutyl-2-oxooctyl\}1,4-diazaspiro[4.5]decan-2-one, 5k. Yield 38\%; $\delta_{\mathrm{H}}\left(\mathrm{CDCl}_{3}, 300 \mathrm{MHz}\right) 8.52$ (dd, J = 4.22 Hz, J = 1.63 Hz; 1H, Q2); 7.92 (dd, J = 8.26 Hz, J=1.53 Hz; $1 \mathrm{H}, \mathrm{Q} 4) ; 7.30$ (dd, J = 8.25 Hz, J=4.20 Hz; $1 \mathrm{H}, \mathrm{Q} 3) ; 6.69$ (bs, $1 \mathrm{H}$, $\left.-\left(\mathrm{CH}_{2}\right)_{3}-\mathrm{NH}-\right) ; 6.33$ (d, J = 2.51 Hz; 1H, Q5); $6.26(\mathrm{~d}, \mathrm{~J}=2.46 \mathrm{~Hz} ; 1 \mathrm{H}$, Q7); 5.98 (d, J=7.55 Hz; $\left.1 \mathrm{H},-\mathrm{NH}-\mathrm{CH}\left(\mathrm{CH}_{3}\right)-\right) ; 3.93-3.89(\mathrm{~m}+\mathrm{s} ; 4 \mathrm{H}$, $\left.-\mathrm{CH}-\mathrm{CH}_{2}-\mathrm{CH}\left(\mathrm{CH}_{3}\right)_{2}, \mathrm{CH}_{3}-\mathrm{O}-\right) ; 3.72-3.54\left(\mathrm{~m} ; 2 \mathrm{H},-\mathrm{CO}-\mathrm{CH}_{2}-\mathrm{NH}-\right)$; $3.51-3.46\left(\mathrm{~m} ; 1 \mathrm{H},-\mathrm{NH}-\mathrm{CH}\left(\mathrm{CH}_{3}\right)-\mathrm{CH}_{2}-\right)$; $3.30-3.20\left(\mathrm{~m} ; 2 \mathrm{H},-\left(\mathrm{CH}_{2}\right)_{2}-\right.$ $\left.\mathrm{CH}_{2}-\mathrm{NH}-\right) ; 2.34\left(\mathrm{t}, \mathrm{J}=6.52 \mathrm{~Hz} ; 1 \mathrm{H},-\mathrm{CO}-\mathrm{CH}_{2}-\mathrm{NH}-\right) ; 1.69-1.62(\mathrm{~m}$; $\left.17 \mathrm{H},-\mathrm{CH}_{2}-\mathrm{CH}_{2}-\mathrm{CH}_{2}-\mathrm{NH}-,-\mathrm{CH}-\mathrm{CH}_{2}-\mathrm{CH}\left(\mathrm{CH}_{3}\right)_{2},-\left(\mathrm{CH}_{2}\right)_{5}-\right) ; 1.29$ (d, $\left.\mathrm{J}=6.29 \mathrm{~Hz} ; 3 \mathrm{H},-\mathrm{NH}-\mathrm{CH}\left(\mathrm{CH}_{3}\right)-\right) ; 0.94$ and $0.92(\mathrm{~d}+\mathrm{d}, \mathrm{J}=5.41 \mathrm{~Hz}$, $\left.\mathrm{J}=5.15 \mathrm{~Hz} ; 6 \mathrm{H},-\mathrm{CH}-\mathrm{CH}_{2}-\mathrm{CH}\left(\mathrm{CH}_{3}\right)_{2}\right) . \delta_{\mathrm{C}}\left(\mathrm{CDCl}_{3}, 75 \mathrm{MHz}\right) 169.77(-\mathrm{NH}-$ $\left.\mathrm{CO}-\mathrm{CH}\left(\mathrm{CH}_{2}-\right)-\right) ; 169.73$ (-CO-CH $\left.\mathrm{CH}_{2}-\mathrm{NH}-\right) ; 159.84-92.12(\mathrm{ArC}) ; 79.33$ $(-\mathrm{N}(\mathrm{CO}-)-\mathrm{C}-)$; 56.53 (-CO-CH$-\mathrm{NH}-) ; 55.65\left(\mathrm{CH}_{3}-\mathrm{O}-\right) ; 48.20(-\mathrm{NH}-$ $\left.\mathrm{CH}\left(\mathrm{CH}_{3}\right)-\mathrm{CH}_{2}-\right) ; 45.30$ (- $\left.\mathrm{CO}-\mathrm{CH}\left(\mathrm{CH}_{2}-\right)-\right) ; 42.28\left(-\left(\mathrm{CH}_{2}\right)_{2}-\mathrm{CH}_{2}-\mathrm{NH}-\right)$; $37.65\left(-\mathrm{CH}_{2}-\mathrm{CH}\left(\mathrm{CH}_{3}\right)_{2}\right) ; 34.46\left(-\mathrm{CH}_{2}-\left(\mathrm{CH}_{2}\right)_{2}-\mathrm{NH}-\right)$; $34.02\left(-\mathrm{CH}_{2}-\right)$; $33.99\left(-\mathrm{CH}_{2}-\right) ; 26.74\left(-\mathrm{CH}_{2}-\right) ; 25.78\left(-\mathrm{CH}_{2}-\mathrm{CH}\left(\mathrm{CH}_{3}\right)_{2}\right) ; 25.11\left(-\mathrm{CH}_{2}-\right.$ $\left.\mathrm{CH}_{2}-\mathrm{CH}_{2}-\mathrm{NH}-\right) ; \quad 23.53 \quad\left(-\mathrm{CH}_{2}-\mathrm{CH}\left(\mathrm{CH}_{3}\right)\left(\mathrm{CH}_{3}\right)\right) ; \quad 23.15 \quad\left(-\mathrm{CH}_{2-}\right.$ $\left.\mathrm{CH}\left(\mathrm{CH}_{3}\right)\left(\mathrm{CH}_{3}\right)\right) ; 22.62\left(-\mathrm{CH}_{2}-\right) ; 22.13\left(-\mathrm{NH}-\mathrm{CH}\left(\mathrm{CH}_{3}\right)-\mathrm{CH}_{2}-\right) ; 20.99$ $\left(-\mathrm{CH}_{2}-\right) \cdot \mathrm{C}_{29} \mathrm{H}_{43} \mathrm{~N}_{5} \mathrm{O}_{3}\left(509.3366 \mathrm{~g} \mathrm{~mol}^{-1}\right): \mathrm{m} / z\left(\mathrm{MH}^{+}\right)=510.2777$.

3-\{7-[(6-Methoxyquinolin-8-yl)amino]-3-aza-1-benzyl-2-oxooctyl\}-1,4-diazaspiro[4.5]decan-2-one, 51. Yield 46\%; $\delta_{\mathrm{H}}\left(\mathrm{CDCl}_{3}\right.$, $300 \mathrm{MHz}) 8.54-8.50(\mathrm{~m} ; 1 \mathrm{H}, \mathrm{Q} 2) ; 8.02-7.93\left(\mathrm{~m} ; 1 \mathrm{H},-\left(\mathrm{CH}_{2}\right)_{3}-\mathrm{NH}-\right.$ ); $7.91(\mathrm{dd}, \mathrm{J}=8.25 \mathrm{~Hz}, \mathrm{~J}=1.41 \mathrm{~Hz} ; 1 \mathrm{H}, \mathrm{Q} 4) ; 7.33-7.17(\mathrm{~m} ; 6 \mathrm{H}, \mathrm{Q} 3$, Ar2-6); 6.32 (bs; 1H, Q5); 6.28 (bs; $1 \mathrm{H}, \mathrm{Q} 7) ; 6.02$ (d, J=8.12 Hz; $\left.1 \mathrm{H},-\mathrm{NH}-\mathrm{CH}\left(\mathrm{CH}_{3}\right)-\mathrm{CH}_{2}-\right) ; 3.87$ and $3.86\left(\mathrm{~s}+\mathrm{s} ; 3 \mathrm{H}, \mathrm{CH}_{3}-\mathrm{O}-\right)$; 3.76$3.73\left(\mathrm{~m} ; 1 \mathrm{H},-\mathrm{CH}-\mathrm{CH}_{2}-\mathrm{Ar}\right)$; 3.67-3.60 (m; $1 \mathrm{H},-\mathrm{NH}-\mathrm{CH}\left(\mathrm{CH}_{3}\right)-$ $\mathrm{CH}_{2-}$ ); 3.36 and 3.34 (d; J =6,00 Hz, 2H, $\left.-\mathrm{CO}-\mathrm{CH}_{2}-\mathrm{NH}-\right)$; $3.30-$ $2.98\left(\mathrm{~m} ; 4 \mathrm{H},-\mathrm{CH}-\mathrm{CH}_{2}-\mathrm{Ar},-\left(\mathrm{CH}_{2}\right)_{2}-\mathrm{CH}_{2}-\mathrm{NH}-\right) ; 2.34(\mathrm{t}, \mathrm{J}=6,44 \mathrm{~Hz}$; $\left.1 \mathrm{H},-\mathrm{CO}-\mathrm{CH}_{2}-\mathrm{NH}-\right)$; $1.91-1.65\left(\mathrm{~m} ; 14 \mathrm{H},-\mathrm{CH}_{2}-\mathrm{CH}_{2}-\mathrm{CH}_{2}-\mathrm{NH}-\right.$, $\left.\left.-\left(\mathrm{CH}_{2}\right)_{5}\right)^{-}\right) ; .31\left(\mathrm{~d}, \mathrm{~J}=6.26 \mathrm{~Hz} ; 3 \mathrm{H},-\mathrm{NH}-\mathrm{CH}\left(\mathrm{CH}_{3}\right)^{-}\right) . \delta_{\mathrm{C}}\left(\mathrm{CDCl}_{3}\right.$, $75 \mathrm{MHz}) 176.14$ (-( $\left.\left.\mathrm{CH}_{2}\right)_{3}-\mathrm{NH}-\mathrm{CO}-\right) ; 172.58\left(-\mathrm{N}-\mathrm{CO}-\mathrm{CH}_{2}-\mathrm{NH}-\right)$; 159.84-92.10 ( $\mathrm{ArC}) ; 82.53$ (-C-); 63.11 (-CO- $\left.\mathrm{CH}_{2}-\mathrm{NH}-\right)$; 55.62 $\left(\mathrm{CH}_{3}-\mathrm{O}-\right) ; 48.91$ (- $\left.\mathrm{CH}-\mathrm{CH}_{2}-\mathrm{Ar}\right) ; 48.10\left(-\mathrm{NH}-\mathrm{CH}\left(\mathrm{CH}_{3}\right)-\mathrm{CH}_{2}-\right)$; $\left.39.76\left(-\mathrm{CH}_{2}\right)_{2}-\mathrm{CH}_{2}-\mathrm{NH}-\right)$; 35.72 and $35.29\left(-\mathrm{CH}_{2}-\right)$; $34.66\left(-\mathrm{CH}_{2}-\right.$ $\left.\left(\mathrm{CH}_{2}\right)_{2}-\mathrm{NH}-\right)$; 33.57 (-CH-CH $\left.2-\mathrm{Ar}\right) ; 26.65\left(-\mathrm{CH}_{2}-\right) ; 24.90\left(-\mathrm{CH}_{2}-\right.$ $\left.\mathrm{CH}_{2}-\mathrm{CH}_{2}-\mathrm{NH}-\right) ; 22.98$ and $22.70\left(-\mathrm{CH}_{2}-\right) ; 20.96\left(-\mathrm{NH}-\mathrm{CH}\left(\mathrm{CH}_{3}\right)-\right.$ $\left.\mathrm{CH}_{2}-\right) . \mathrm{C}_{32} \mathrm{H}_{41} \mathrm{~N}_{5} \mathrm{O}_{3}\left(543.3209 \mathrm{~g} \mathrm{~mol}^{-1}\right): \mathrm{m} / z\left(\mathrm{MH}^{+}\right)=544.2916$.

3-\{7-[(6-Methoxyquinolin-8-yl)amino]-3-aza-2-oxooctyl\}-3-methyl1,4-diazaspiro[4.5]decan-2-one, $5 \mathrm{~m}$. Yield $88 \% ; \delta_{\mathrm{H}}\left(\mathrm{CDCl}_{3}, 300 \mathrm{MHz}\right)$ $8.52(\mathrm{dd}, \mathrm{J}=4.22 \mathrm{~Hz}, \mathrm{~J}=1.65 \mathrm{~Hz} ; 1 \mathrm{H}, \mathrm{Q} 2) ; 7.92(\mathrm{dd}, \mathrm{J}=8.27 \mathrm{~Hz}$, $\mathrm{J}=1.55 \mathrm{~Hz} ; 1 \mathrm{H}, \mathrm{Q} 4) ; 7.30$ (dd, J=8.22 Hz, J=4.25 Hz; 1H, Q3); 6.68 (d, 
$\left.\mathrm{J}=4.82 \mathrm{~Hz} ; 1 \mathrm{H},-\left(\mathrm{CH}_{2}\right)_{3}-\mathrm{NH}-\right) ; 6.33(\mathrm{~d}, \mathrm{~J}=2.48 \mathrm{~Hz} ; 1 \mathrm{H}, \mathrm{Q} 5) ; 6.26(\mathrm{~d}$, $\mathrm{J}=2.43 \mathrm{~Hz} ; 1 \mathrm{H}, \mathrm{Q} 7$ ); 5.99 (bs; $1 \mathrm{H},-\mathrm{NH}-\mathrm{CH}\left(\mathrm{CH}_{3}\right)-\mathrm{CH}_{2}-$ ); 3.89 (bs; $4 \mathrm{H}$, $\left.\mathrm{CH}_{3}-\mathrm{O}-,-\mathrm{NH}-\mathrm{CO}-\mathrm{CHH}-\right)$; 3.68-3.60 (m; $2 \mathrm{H},-\mathrm{NH}-\mathrm{CO}-\mathrm{CHH}-,-\mathrm{NH}-$ $\left.\mathrm{CH}\left(\mathrm{CH}_{3}\right)-\right)$; 3.51 (q, J=6.88 Hz; $\left.-\mathrm{CO}-\mathrm{CH}\left(\mathrm{CH}_{3}\right)-\mathrm{NH}-\right)$; 3.31-3.16 (m; $\left.2 \mathrm{H},-\left(\mathrm{CH}_{2}\right)_{2}-\mathrm{CH}_{2}-\mathrm{NH}-\right) ; 1.83$ (d, J = 4.34 Hz; $\left.1 \mathrm{H},-\mathrm{CO}-\mathrm{CH}\left(\mathrm{CH}_{3}\right)-\mathrm{NH}-\right)$; $1.71-1.57\left(\mathrm{~m} ; 10 \mathrm{H} ;-\left(\mathrm{CH}_{2}\right)_{5}-\right) ; 1.52-1.46\left(\mathrm{~m} ; 4 \mathrm{H},-\mathrm{CH}_{2}-\mathrm{CH}_{2}-\mathrm{CH}_{2}-\mathrm{NH}-\right.$ ); 1.33 and $1.30\left(\mathrm{~d}+\mathrm{d} ; \mathrm{J}=7.05 \mathrm{~Hz}, \mathrm{~J}=7.01 \mathrm{~Hz} ; 3 \mathrm{H},-\mathrm{CO}-\mathrm{CH}\left(\mathrm{CH}_{3}\right)\right.$ $\mathrm{NH}-) ; 1.29\left(\mathrm{~d}, \mathrm{~J}=6.35 \mathrm{~Hz} ; 3 \mathrm{H},-\mathrm{NH}-\mathrm{CH}\left(\mathrm{CH}_{3}\right)-\mathrm{CH}_{2}-\right) . \delta_{\mathrm{C}}\left(\mathrm{CDCl}_{3}\right.$, $75 \mathrm{MHz}) \quad 177.48 \quad\left(-\mathrm{N}-\mathrm{CO}-\mathrm{CH}\left(\mathrm{CH}_{3}\right)-\right) ; 169.66 \quad\left(-\mathrm{NH}-\mathrm{CO}-\mathrm{CH}_{2}-\right)$; 159.82-92.12 ( $\mathrm{ArC}) ; 79.12(-\mathrm{N}-\mathrm{C}-\mathrm{NH}-) ; 55.64\left(\mathrm{CH}_{3}-\mathrm{O}-\right) ; 53.80(-\mathrm{NH}-$ $\left.\mathrm{CH}\left(\mathrm{CH}_{3}\right)-\mathrm{CH}_{2}-\right) ; 48.20\left(-\mathrm{CO}-\mathrm{CH}\left(\mathrm{CH}_{3}\right)-\mathrm{NH}-\right) ; 45.32\left(-\mathrm{NH}-\mathrm{CO}-\mathrm{CH}_{2}-\right.$ $\mathrm{N}-)$; $42.40\left(-\mathrm{CH}\left(\mathrm{CH}_{3}\right)-\left(\mathrm{CH}_{2}\right)_{2}-\mathrm{CH}_{2}-\right) ; 39.73\left(-\mathrm{CH}_{2}-\right)$; $37.58\left(-\mathrm{CH}_{2}-\right)$; $\left.34.43\left(-\mathrm{CH}\left(\mathrm{CH}_{3}\right)-\mathrm{CH}_{2}-\left(\mathrm{CH}_{2}\right)_{2}\right)-\right) ; 27.31\left(-\mathrm{CH}_{2}-\right) ; 26.61\left(-\mathrm{CH}\left(\mathrm{CH}_{3}\right)-\right.$ $\left.\mathrm{CH}_{2}-\mathrm{CH}_{2}-\mathrm{CH}_{2}-\right) ; 24.95 \quad\left(-\mathrm{NH}-\mathrm{CH}\left(\mathrm{CH}_{3}\right)-\mathrm{CH}_{2}-\right) ; 23.00 \quad\left(-\mathrm{CH}_{2}-\right)$; $22.46\left(-\mathrm{CH}_{2}{ }^{-}\right) ; 20.99\left(-\mathrm{NH}-\mathrm{CH}\left(\mathrm{CH}_{3}\right)-\mathrm{CH}_{2-}\right) ; 18.10$ and $18.07(-\mathrm{CO}-$ $\left.\mathrm{CH}\left(\mathrm{CH}_{3}\right)-\mathrm{NH}-\right) . \quad \mathrm{C}_{26} \mathrm{H}_{37} \mathrm{~N}_{5} \mathrm{O}_{3} \quad\left(467.2896 \mathrm{~g} \mathrm{~mol}^{-1}\right): \quad \mathrm{m} / z \quad\left(\mathrm{MH}^{+}\right)=$ 468.2162; $m / z\left(\mathrm{MNa}^{+}\right)=490.1942$.

3-\{7-[(6-Methoxyquinolin-8-yl)amino]-3-aza-2-oxooctyl\}-3-benzyl1,4-diazaspiro[4.5]decan-2-one, $\mathbf{5 n}$. Yield $80 \% ; \delta_{\mathrm{H}}\left(\mathrm{CDCl}_{3}, 300 \mathrm{MHz}\right)$ $8.50(\mathrm{dd}, \mathrm{J}=4.18 \mathrm{~Hz}, \mathrm{~J}=1.41 \mathrm{~Hz} ; 1 \mathrm{H}, \mathrm{Q} 2) ; 7.90-7.89$ (dd + dd, $\mathrm{J}=8.00 \mathrm{~Hz}, \mathrm{~J}=1.60 \mathrm{~Hz}$ and $\mathrm{J}=8.22 \mathrm{~Hz}, \mathrm{~J}=1.59 \mathrm{~Hz} ; 1 \mathrm{H}, \mathrm{Q} 4) ; 7.30-$ 7.21 (m; 6H, Q3, Ar2-6); 6.31 (d, J=2.15 Hz; $1 \mathrm{H}, \mathrm{Q} 5) ; 6.26$ (d, $\mathrm{J}=2.31 \mathrm{~Hz} ; 1 \mathrm{H}, \quad \mathrm{Q}) ; \quad 6.05-5.97\left(\mathrm{~m} ; 2 \mathrm{H}, \quad-\mathrm{NH}-\mathrm{CH}\left(\mathrm{CH}_{3}\right)-\mathrm{CH}_{2-}\right.$ $\left.\left(\mathrm{CH}_{2}\right)_{2}-\mathrm{NH}-\right) ; 4.00-3.95(\mathrm{~m} ; 1 \mathrm{H},-\mathrm{NH}-\mathrm{CO}-\mathrm{CHH}-) ; 3.86\left(\mathrm{~s} ; 3 \mathrm{H}, \mathrm{CH}_{3}-\right.$ $\mathrm{O}-$ ); 3.61-3.49 (m; $\left.2 \mathrm{H},-\mathrm{NH}-\mathrm{CH}\left(\mathrm{CH}_{3}\right)-\mathrm{CH}_{2-},-\mathrm{CH}(\mathrm{NH}-)-\mathrm{CH}_{2}-\mathrm{Ar}\right)$; $3.52(2)$ and $3.51(6)(\mathrm{d}+\mathrm{d}, \mathrm{J}=15.91 \mathrm{~Hz}, \mathrm{~J}=16.01 \mathrm{~Hz} ; 1 \mathrm{H},-\mathrm{NH}-\mathrm{CO}-$ $\mathrm{CHH}-)$; 3.19-3.09 (m + d, J =5.31 Hz, $\left.4 \mathrm{H},-\mathrm{CH}_{2}-\mathrm{Ar},-\left(\mathrm{CH}_{2}\right)_{2}-\mathrm{CH}_{2}-\right)$; $3.01\left(\mathrm{~d}, \mathrm{~J}=4.57 \mathrm{~Hz} ; 1 \mathrm{H},-\mathrm{CH}(\mathrm{NH}-)-\mathrm{CH}_{2}-\mathrm{Ar}\right) ; 1.86-1.83(\mathrm{~m} ; 1 \mathrm{H}$ - $\left.\mathrm{CO}-\mathrm{CH}\left(\mathrm{CH}_{2}-\mathrm{Ar}\right)-\mathrm{NH}-\right)$; $1.74-1.68\left(\mathrm{~m} ; 2 \mathrm{H},-\mathrm{CH}_{2}-\mathrm{CH}_{2}-\mathrm{CH}_{2}-\mathrm{NH}-\right)$; 1.65-1.44 (m; $\left.12 \mathrm{H},-\mathrm{CH}_{2}-\mathrm{CH}_{2}-\mathrm{CH}_{2}-\mathrm{NH}-,-\left(\mathrm{CH}_{2}\right)_{5}-\right) ; 1.28$ and 1.27 $\left(\mathrm{d}+\mathrm{d}, \mathrm{J}=6.38 \mathrm{~Hz}, \mathrm{~J}=6.34 \mathrm{~Hz} ; 3 \mathrm{H},-\mathrm{NH}-\mathrm{CH}\left(\mathrm{CH}_{3}\right)-\right) . \delta_{\mathrm{C}}\left(\mathrm{CDCl}_{3}\right.$, $75 \mathrm{MHz}) 174.96$ (-N(CO-)-); 168.59 (-NH-CO- $\mathrm{CH}_{2-}$ ); 159.27-91.54 $(\mathrm{ArC}) ; 78.47\left(-\mathrm{CO}-\mathrm{CH}\left(\mathrm{CH}_{2}-\mathrm{Ph}\right)-\mathrm{NH}-\right) ; 58.43(-\mathrm{N}(\mathrm{CO}-)-\mathrm{C}-) ; 55.05$ $\left(\mathrm{CH}_{3}-\mathrm{O}-\right) ; 47.58\left(-\mathrm{NH}-\mathrm{CH}\left(\mathrm{CH}_{3}\right)-\mathrm{CH}_{2}-\right) ; 44.26\left(-\mathrm{CO}-\mathrm{CH}_{2}-\mathrm{N}(\mathrm{CO}-\right.$ )$-) ; \quad 41.84 \quad\left(-\left(\mathrm{CH}_{2}\right)_{2}-\mathrm{CH}_{2}-\mathrm{NH}-\right) ; \quad 39.16 \quad\left(-\mathrm{CH}_{2}-\mathrm{Ph}\right) ; \quad 36.60$ $\left(-\mathrm{CH}_{2}-\left(\mathrm{CH}_{2}\right)_{2}-\mathrm{NH}-\right) ; 33.81\left(-\mathrm{CH}_{2}-\right) ; 33.39\left(-\mathrm{CH}_{2}-\right) ; 26.94\left(-\mathrm{CH}_{2}-\right.$ $\left.\mathrm{CH}_{2}-\mathrm{CH}_{2}-\right)$; $26.15\left(-\mathrm{CH}_{2}-\right) ; 22.51\left(-\mathrm{CH}_{2}-\right) ; 21.94\left(-\mathrm{CH}_{2}-\right) ; 20.44$ $\left(-\mathrm{NH}-\mathrm{CH}\left(\mathrm{CH}_{3}\right)-\right) . \mathrm{C}_{32} \mathrm{H}_{41} \mathrm{~N}_{5} \mathrm{O}_{3} \quad\left(543.3209 \mathrm{~g} \mathrm{~mol}^{-1}\right): \mathrm{m} / z\left(\mathrm{MH}^{+}\right)=$ 544.2916.

3-\{7-[(6-Methoxyquinolin-8-yl)amino]-3-aza-1-methyl-2-oxooctyl\}-3-methyl-1,4-diazaspiro[4.5]decan-2-one, 5o. Yield 46\%; $\delta_{\mathrm{H}}$ $\left(\mathrm{CDCl}_{3}, 300 \mathrm{MHz}\right) 8.49(\mathrm{dd}, \mathrm{J}=4.18 \mathrm{~Hz}, \mathrm{~J}=1.56 \mathrm{~Hz} ; 1 \mathrm{H}, \mathrm{Q} 2) ; 7.88$ (dd, J = 8.24 Hz, J = $1.52 \mathrm{~Hz} ; 1 \mathrm{H}, \mathrm{Q} 4) ; 7.77$ (bs; $1 \mathrm{H},-\mathrm{CH}_{2}-\mathrm{NH}-\mathrm{CO}-$ ); $7.27(\mathrm{dd}, \mathrm{J}=8.22 \mathrm{~Hz}, \mathrm{~J}=4.21 \mathrm{~Hz} ; 1 \mathrm{H}, \mathrm{Q} 3) ; 6.30(\mathrm{~d}, \mathrm{~J}=2.41 \mathrm{~Hz} ; 1 \mathrm{H}$, Q5); 6.24 (bs; $1 \mathrm{H}, \mathrm{Q} 7) ; 5.99$ (bs; $\left.1 \mathrm{H},-\mathrm{NH}-\mathrm{CH}\left(\mathrm{CH}_{3}\right)-\right) ; 3.86$ (s; $3 \mathrm{H}$, $\mathrm{CH}_{3}-\mathrm{O}-$ ); 3.73 (q, J = 7.36 Hz; $1 \mathrm{H},-\mathrm{NH}-\mathrm{CO}-\mathrm{CH}\left(\mathrm{CH}_{3}\right)-$ ); 3.59 (bs; $\left.1 \mathrm{H}, \quad-\mathrm{NH}-\mathrm{CH}\left(\mathrm{CH}_{3}\right)-\mathrm{CH}_{2}-\right) ; \quad 3.47-3.44 \quad(\mathrm{q}+\mathrm{q} ; \quad \mathrm{J}=6.39 \mathrm{~Hz}$, $\left.\mathrm{J}=6.71 \mathrm{~Hz} ; 1 \mathrm{H},-\mathrm{CO}-\mathrm{CH}\left(\mathrm{CH}_{3}\right)-\mathrm{NH}-\right) ; 3.37-3.27\left(\mathrm{~m} ; 1 \mathrm{H},-\mathrm{CH}_{2}-\right.$ $\mathrm{CH}_{2}-\mathrm{CHH}-$ ); 3.20-3.09 (m; $\left.1 \mathrm{H},-\mathrm{CH}_{2}-\mathrm{CH}_{2}-\mathrm{CHH}-\right)$; $1.89-1.77$ (m; $\left.1 \mathrm{H},-\mathrm{CO}-\mathrm{CH}\left(\mathrm{CH}_{3}\right)-\mathrm{NH}-\right) ; 1.70-1.59\left(\mathrm{~m} ; 14 \mathrm{H},-\left(\mathrm{CH}_{2}\right)_{5-},-\mathrm{CH}_{2}-\mathrm{CH}_{2}-\right.$ $\left.\mathrm{CH}_{2}-\mathrm{NH}-\right) ; 1.45-1.34\left(\mathrm{~m} ; 3 \mathrm{H},-\mathrm{NH}-\mathrm{CO}-\mathrm{CH}\left(\mathrm{CH}_{3}\right)-\right) ; 1.27$ (d, $\left.\mathrm{J}=6.57 \mathrm{~Hz} ; 6 \mathrm{H},-\mathrm{NH}-\mathrm{CH}\left(\mathrm{CH}_{3}\right)-,-\mathrm{CO}-\mathrm{CH}\left(\mathrm{CH}_{3}\right)-\mathrm{NH}-\right) . \delta_{\mathrm{C}}\left(\mathrm{CDCl}_{3}\right.$, $75 \mathrm{MHz}) 177.75$ (-NH-CO-CH(CH$\left.\left.{ }_{3}\right)-\right)$; $173.04\left(-\mathrm{CO}-\mathrm{CH}\left(\mathrm{CH}_{3}\right)-\mathrm{NH}-\right.$ ); 159.82-92.07 ( $\mathrm{ArC}) ; 80.13(-\mathrm{N}(\mathrm{CO}-)-\mathrm{C}-)$; $55.80\left(\mathrm{CH}_{3}-\mathrm{O}-\right) ; 55.62$ $\left(-\mathrm{CO}-\mathrm{CH}\left(\mathrm{CH}_{3}\right)-\mathrm{NH}-\right) ; 54.06\left(-\mathrm{NH}-\mathrm{CH}\left(\mathrm{CH}_{3}\right)-\mathrm{CH}_{2}-\right) ; 48.12(-\mathrm{NH}-$ $\left.\mathrm{CO}-\mathrm{CH}\left(\mathrm{CH}_{3}\right)-\right)$; $39.66\left(-\left(\mathrm{CH}_{2}\right)_{2}-\mathrm{CH}_{2}-\mathrm{NH}-\right) ; 39.59\left(-\mathrm{CH}_{2}-\right) ; 37.87$ $\left(-\mathrm{CH}_{2}-\right)$; $34.36\left(-\mathrm{CH}_{2}-\left(\mathrm{CH}_{2}\right)_{2}-\mathrm{NH}-\right)$; 26.68 and $26,54\left(-\mathrm{CH}_{2}-\right)$; $25.14\left(-\mathrm{CH}_{2}-\mathrm{CH}_{2}-\mathrm{CH}_{2}-\right) ; 23.42 \quad\left(-\mathrm{NH}-\mathrm{CH}\left(\mathrm{CH}_{3}\right)-\mathrm{CH}_{2}-\right) ; 20.96$ $\left(-\mathrm{CO}-\mathrm{CH}\left(\mathrm{CH}_{3}\right)-\mathrm{NH}-\right) ; 17.80\left(-\mathrm{CH}_{2}-\right)$; $17.68\left(-\mathrm{CH}_{2}-\right)$; 16.16 (-CO$\left.\mathrm{CH}\left(\mathrm{CH}_{3}\right)-\right) . \mathrm{C}_{27} \mathrm{H}_{39} \mathrm{~N}_{5} \mathrm{O}_{3}\left(481.3053 \mathrm{~g} \mathrm{~mol}^{-1}\right): \mathrm{m} / z\left(\mathrm{M}^{+}\right)=481.3849$.

3-\{7-[(6-Methoxyquinolin-8-yl)amino]-3-aza-1-methyl-2-oxooctyl]-3-[(2-methylthio)ethyl]-1,4-diazaspiro[4.5] decan-2-one, 5p. Yield 80\%; $\delta_{\mathrm{H}}\left(\mathrm{CDCl}_{3}, 300 \mathrm{MHz}\right) 8.49(3)$ and $8.49(0)(\mathrm{dd}+\mathrm{dd}$, $\mathrm{J}=4.21 \mathrm{~Hz}, \mathrm{~J}=1.46 \mathrm{~Hz}$ and $\mathrm{J}=4.14 \mathrm{~Hz}, \mathrm{~J}=1.41 \mathrm{~Hz} ; 1 \mathrm{H}, \mathrm{Q} 2) ; 7.88$ $(\mathrm{dd}, \mathrm{J}=8.25 \mathrm{~Hz}, \mathrm{~J}=1.56 \mathrm{~Hz} ; 1 \mathrm{H}, \mathrm{Q} 4) ; 7.70$ and $7.68(\mathrm{t}+\mathrm{t}, \mathrm{J}=5.16 \mathrm{~Hz}$ and $\left.\mathrm{J}=4.96 \mathrm{~Hz} ; \quad 1 \mathrm{H}, \quad-\left(\mathrm{CH}_{2}\right)_{3}-\mathrm{NH}-\right) ; 7.27 \quad(\mathrm{dd}, \mathrm{J}=8.25 \mathrm{~Hz}$, $\mathrm{J}=4.21 \mathrm{~Hz} ; 1 \mathrm{H}, \mathrm{Q} 3) ; 6.30$ (d, J=2.47 Hz; 1H, Q5); 6.24 (bs; 1H, Q7); $5.98\left(\mathrm{~d}, \mathrm{~J}=7.92 \mathrm{~Hz} ; 1 \mathrm{H},-\mathrm{NH}-\mathrm{CH}\left(\mathrm{CH}_{3}\right)-\mathrm{CH}_{2}-\right) ; 3.85(7) 3.85(4)$ $\left(\mathrm{s}+\mathrm{s} ; 3 \mathrm{H}, \mathrm{CH}_{3}-\mathrm{O}-\right) ; 3.74\left(\mathrm{q}, \mathrm{J}=7.36 \mathrm{~Hz} ; 1 \mathrm{H},-\mathrm{CO}-\mathrm{CH}\left(\mathrm{CH}_{3}\right)-\right) ; 3.64-$ $3.54\left(\mathrm{~m} ; 2 \mathrm{H},-\mathrm{NH}-\mathrm{CH}\left(\mathrm{CH}_{3}\right)-\mathrm{CH}_{2-},-\mathrm{CO}-\mathrm{CH}\left(\mathrm{CH}_{2}-\right)-\mathrm{NH}-\right)$; $3.34-$ $3.26\left(\mathrm{~m} ; 1 \mathrm{H},-\left(\mathrm{CH}_{2}\right)_{2}-\mathrm{CHH}-\right) ; 3.17-3.09\left(\mathrm{~m} ; 1 \mathrm{H},-\left(\mathrm{CH}_{2}\right)_{2}-\mathrm{CHH}-\right)$; 2.59 and $2.56\left(\mathrm{t}+\mathrm{t}, \mathrm{J}=7.30 \mathrm{~Hz}, \mathrm{~J}=7.02 \mathrm{~Hz} ; 2 \mathrm{H},-\mathrm{CH}_{2}-\mathrm{CH}_{2}-\mathrm{S}-\mathrm{CH}_{3}\right)$; $2.33-2.28\left(\mathrm{~m} ; 2 \mathrm{H},-\mathrm{CH}_{2}-\mathrm{CH}_{2}-\mathrm{S}-\right) ; 2.04-2.01\left(\mathrm{~s}+\mathrm{s} ; 3 \mathrm{H},-\left(\mathrm{CH}_{2}\right)_{2}-\mathrm{S}-\right.$ $\left.\mathrm{CH}_{3}\right)$; $1.87-1.79\left(\mathrm{~m} ; 5 \mathrm{H},-\mathrm{CH}_{2}-\mathrm{CH}_{2}-\mathrm{CH}_{2}-,-\mathrm{CO}-\mathrm{CH}\left(\mathrm{CH}_{2}-\right)-\mathrm{NH}-\right)$; $1.72-1.56\left(\mathrm{~m} ; 10 \mathrm{H},-\left(\mathrm{CH}_{2}\right)_{5}-\right) ; 1.61(\mathrm{~d}, \mathrm{~J}=7.39 \mathrm{~Hz} ; 3 \mathrm{H},-\mathrm{CO}-$ $\left.\mathrm{CH}\left(\mathrm{CH}_{3}\right)-\right) ; 1.27\left(\mathrm{~d}, \mathrm{~J}=6.35 \mathrm{~Hz} ; 3 \mathrm{H},-\mathrm{NH}-\mathrm{CH}\left(\mathrm{CH}_{3}\right)-\right) . \delta_{\mathrm{C}}\left(\mathrm{CDCl}_{3}\right.$, $75 \mathrm{MHz}) 176.52$ and $176.49\left(-\mathrm{CO}-\mathrm{CH}\left(\mathrm{CH}_{2}\right)-\mathrm{NH}-\right)$; $172.84(-\mathrm{NH}-$ $\left.\mathrm{CO}-\mathrm{CH}\left(\mathrm{CH}_{3}\right)-\right)$; 159.84 and 159.82 (QC6); 144.33 (QC2); 144.70 (QC8); 135.75 and 135.73 (QC4); 135.16 (QC10); 130.30 (QC9); 122.25 (QC3); 97.08 and 97.06 (QC7); 92.06 (QC5); 80.16 (-CO$\left.\mathrm{CH}\left(\mathrm{CH}_{2}{ }^{-}\right)-\mathrm{NH}-\right)$; 56.92 and $56.87\left(-\mathrm{N}-\mathrm{C}\left(-\mathrm{CH}_{2}-\right)-\mathrm{NH}-\right) ; 55.63$ $\left(\mathrm{CH}_{3}-\mathrm{O}-\right) ; 55.49$ (-CO-CH$\left.\left(\mathrm{CH}_{3}\right)-\right) ; 48.20$ and 48.14 (-NH$\left.\mathrm{CH}\left(\mathrm{CH}_{3}\right)-\mathrm{CH}_{2-}\right)$; $39.73\left(-\left(\mathrm{CH}_{2}\right)_{2}-\mathrm{CH}_{2-}\right)$; $39.66\left(-\mathrm{CH}_{2}-\left(\mathrm{CH}_{2}\right)_{4}{ }^{-}\right)$; 37.84 and $37.82\left(-\left(\mathrm{CH}_{2}\right)_{4}-\mathrm{CH}_{2}-\right)$; $34.41\left(-\mathrm{CH}_{2}-\left(\mathrm{CH}_{2}\right)_{2}-\right)$; 34.05 and $34.00\left(-\left(\mathrm{CH}_{2}\right)_{2}-\mathrm{CH}_{2}-\left(\mathrm{CH}_{2}\right)_{2}-\right) ; 31.47\left(-\mathrm{CH}_{2}-\mathrm{CH}_{2}-\mathrm{S}-\right) ; 30.76$ and $30.73\left(-\mathrm{CH}_{2}-\mathrm{CH}_{2}-\mathrm{S}-\right) ; 26.70$ and $26.64\left(-\mathrm{CH}_{2}-\mathrm{CH}_{2}-\mathrm{CH}_{2}-\right) ; 23.35$ $\left(-\left(\mathrm{CH}_{2}\right)_{3}-\mathrm{CH}_{2}-\mathrm{CH}_{2}-\right) ; 22.51 \quad\left(-\mathrm{CH}_{2}-\mathrm{CH}_{2}-\left(\mathrm{CH}_{2}\right)_{3}-\right) ; 20.92$ and $20.91\left(-\mathrm{NH}-\mathrm{CH}\left(\mathrm{CH}_{3}\right)-\mathrm{CH}_{2}-\right)$; $16.29\left(-\mathrm{CH}_{2}-\mathrm{S}-\mathrm{CH}_{3}\right) ; 15.67$ (-CO$\left.\mathrm{CH}\left(\mathrm{CH}_{3}\right)-\right) . \mathrm{C}_{29} \mathrm{H}_{43} \mathrm{~N}_{5} \mathrm{O}_{3} \mathrm{~S}\left(541.31 \mathrm{~g} \mathrm{~mol}^{-1}\right): \mathrm{m} / z\left(\mathrm{MH}^{+}\right)=542.87$; $m / z\left(\mathrm{MNa}^{+}\right)=564.87$.

3-\{7-[(6-Methoxyquinolin-8-yl)amino]-3-aza-2-oxooctyl\}-3-benzyl1,4-diazaspiro-8-methyl[4.5]decan-2-one, 5q. Yield 62\%; $\delta_{\mathrm{H}}\left(\mathrm{CDCl}_{3}\right.$, $300 \mathrm{MHz}) 8.52(\mathrm{dd}, \mathrm{J}=4.21 \mathrm{~Hz}, \mathrm{~J}=1.61 \mathrm{~Hz} ; 1 \mathrm{H}, \mathrm{Q} 2) ; 7.90$ and 7.89 $(\mathrm{dd}+\mathrm{dd}, \mathrm{J}=8.26 \mathrm{~Hz}, \mathrm{~J}=1.77 \mathrm{~Hz}$ and $\mathrm{J}=8.28 \mathrm{~Hz}, \mathrm{~J}=1.78 \mathrm{~Hz} ; 1 \mathrm{H}, \mathrm{Q} 4)$; 7.31-7.20 (m; 6H, Q3, Ar2-6); 6.32 (d, J = 2.04 Hz; 1H, Q5); 6.26 (d, $\mathrm{J}=2.44 \mathrm{~Hz} ; 1 \mathrm{H}, \mathrm{Q} 7) ; 6.02-5.97\left(\mathrm{~m} ; 2 \mathrm{H},-\mathrm{NH}-\mathrm{CH}\left(\mathrm{CH}_{3}\right)-\mathrm{CH}_{2^{-}},-\mathrm{NH}-\right.$ $\left.\mathrm{CO}-\mathrm{CH}_{2}-\right) ; 3.98$ (d, J=15.96 Hz; $\left.1 \mathrm{H},-\mathrm{NH}-\mathrm{CO}-\mathrm{CHH}-\right) ; 3.86(\mathrm{~s} ; 3 \mathrm{H}$, $\mathrm{CH}_{3}-\mathrm{O}-$ ); 3.80 (q, J=4.87 Hz; $\left.1 \mathrm{H},-\mathrm{NH}-\mathrm{CH}\left(\mathrm{CH}_{3}\right)-\mathrm{CH}_{2}-\right)$; 3.62-3.57 (m; $\left.1 \mathrm{H},-\mathrm{CO}-\mathrm{CH}\left(\mathrm{CH}_{2}-\right)-\mathrm{NH}-\right)$; 3.50 and $3.49(\mathrm{~d}+\mathrm{d}, \mathrm{J}=15.99 \mathrm{~Hz}$, $\mathrm{J}=16.01 \mathrm{~Hz} ; 1 \mathrm{H},-\mathrm{NH}-\mathrm{CO}-\mathrm{CHH}-) ; 3.19-2.95\left(\mathrm{~m} ; 4 \mathrm{H},-\left(\mathrm{CH}_{2}\right)_{2}-\mathrm{CH}_{2-}\right.$, $\left.-\mathrm{CH}_{2}-\mathrm{Ph}\right) ; 2.00-1.39\left(\mathrm{~m} ; 14 \mathrm{H},-\mathrm{CH}_{2}-\mathrm{CH}_{2}-\mathrm{CH}_{2}-,-\mathrm{CH}\left(\mathrm{CH}_{2}-\right)-\mathrm{NH}-\right.$, $\left.-\left(\mathrm{CH}_{2}\right)_{2}-\mathrm{CH}\left(\mathrm{CH}_{3}\right)-\left(\mathrm{CH}_{2}\right)_{2}-\right) ; 1.28(1)$ and $1.27(6)(\mathrm{d}+\mathrm{d}, \mathrm{J}=6.35 \mathrm{~Hz}$ and $\left.\mathrm{J}=6.38 \mathrm{~Hz} ; 3 \mathrm{H}, \quad-\mathrm{NH}-\mathrm{CH}\left(\mathrm{CH}_{3}\right)-\right) ; 0.86$ and $0.85(\mathrm{~d}+\mathrm{d}$, $\mathrm{J}=5.28 \mathrm{~Hz}$ and $\left.\mathrm{J}=5.42 \mathrm{~Hz} ; 3 \mathrm{H},-\left(\mathrm{CH}_{2}\right)_{2}-\mathrm{CH}\left(\mathrm{CH}_{3}\right)-\left(\mathrm{CH}_{2}\right)_{2}-\right) . \delta_{\mathrm{C}}\left(\mathrm{CDCl}_{3}\right.$, $75 \mathrm{MHz}) \quad 175.55$ (-CO-CH(CH 2$)-\mathrm{NH}-)$; 169.12 (-NH-CO-CH $2_{2}^{-}$; 159.85 (QC6); 145.36 (QC2); 144.75 and 144.72 (QC8); 139.98 (ArC1); 135.77 (QC4); 135.19 (QC10); 130.37 (ArC3 + ArC5); 130.33 (QC9); $128.98(\operatorname{ArC2}+\operatorname{ArC6}) ; 127.52(\operatorname{ArC4}) ; 122.30(\mathrm{QC3}) ; 97.10(\mathrm{QC7}) ;$ 92.11 and 92.09 (QC5); $78.79\left(-\mathrm{CO}-\mathrm{CH}\left(\mathrm{CH}_{2}{ }^{-}\right)-\mathrm{NH}-\right)$; 58.97 and $58.95\left(-\mathrm{N}(\mathrm{CO}-)-\mathrm{C}\left(-\mathrm{CH}_{2}-\right)-\mathrm{NH}-\right)$; $55.62\left(\mathrm{CH}_{3}-\mathrm{O}-\right) ; 48.15(-\mathrm{NH}-$ $\left.\mathrm{CH}\left(\mathrm{CH}_{3}\right)-\mathrm{CH}_{2}-\right) ; \quad 44.80 \quad\left(-\mathrm{CO}-\mathrm{CH}_{2}-\mathrm{N}-\right) ; \quad 39.72 \quad\left(-\left(\mathrm{CH}_{2}\right)_{2}-\mathrm{CH}_{2}-\right)$; 36.99 and $36.94\left(-\mathrm{CH}_{2}-\mathrm{Ph}\right)$; 34.43 and $34.39\left(-\left(\mathrm{CH}_{2}\right)_{2}-\mathrm{CH}\left(\mathrm{CH}_{3}\right)-\right.$ $\left.\left(\mathrm{CH}_{2}\right)_{2}-\right) ; \quad 33.75 \quad\left(-\mathrm{CH}_{2}-\left(\mathrm{CH}_{2}\right)_{2}-\right) ; \quad 31.63 \quad\left(-\mathrm{CH}_{2}-\mathrm{CH}_{2}-\mathrm{CH}\left(\mathrm{CH}_{3}\right)-\right.$ $\left.\left(\mathrm{CH}_{2}\right)_{2}-\right) ; 31.52\left(-\left(\mathrm{CH}_{2}\right)_{2}-\mathrm{CH}\left(\mathrm{CH}_{3}\right)-\mathrm{CH}_{2}-\mathrm{CH}_{2}-\right) ; 30.89\left(-\mathrm{CH}_{2}-\mathrm{CH}_{2-}\right.$ $\left.\mathrm{CH}\left(\mathrm{CH}_{3}\right)-\left(\mathrm{CH}_{2}\right)_{2}-\right) ; \quad 30.85 \quad\left(-\left(\mathrm{CH}_{2}\right)_{2}-\mathrm{CH}\left(\mathrm{CH}_{3}\right)-\mathrm{CH}_{2}-\mathrm{CH}_{2}-\right) ; 26.72$ $\left(-\mathrm{CH}_{2}-\mathrm{CH}_{2}-\mathrm{CH}_{2}-\right) ; 22.23\left(-\mathrm{NH}-\mathrm{CH}\left(\mathrm{CH}_{3}\right)-\mathrm{CH}_{2}-\right) ; 21.03\left(-\left(\mathrm{CH}_{2}\right)_{2}-\mathrm{CH}\right.$ $\left.\left(\mathrm{CH}_{3}\right)-\left(\mathrm{CH}_{2}\right)_{2}{ }^{-}\right) . \quad \mathrm{C}_{33} \mathrm{H}_{43} \mathrm{~N}_{5} \mathrm{O}_{3} \quad\left(557.3366 \mathrm{~g} \mathrm{~mol}^{-1}\right): \quad \mathrm{m} / \mathrm{z} \quad\left(\mathrm{M}^{+}\right)=$ 557.2001.

3-\{7-[(6-Methoxyquinolin-8-yl)amino]-3-aza-2-oxooctyl\}-3-benzyl1,4-diazaspiro[4.4]nonan-2-one, 5r. Yield 78\%; $\delta_{\mathrm{H}}\left(\mathrm{CDCl}_{3}, 300 \mathrm{MHz}\right)$ 8.59 (dd, J=4.16 Hz, J=1.39 Hz; $1 \mathrm{H}, \mathrm{Q} 2) ; 7.99$ (d, J=8.08 Hz; $1 \mathrm{H}$, Q4); 7.39-7.25 (m; 6H, Q3, $-\mathrm{ArH}) ; 6.40(\mathrm{~d}, \mathrm{~J}=2.34 \mathrm{~Hz} ; 1 \mathrm{H}, \mathrm{Q} 5) ; 6.34$ (s; $1 \mathrm{H}, \mathrm{Q} 7) ; 6.10\left(\mathrm{~s} ; 1 \mathrm{H},-\left(\mathrm{CH}_{2}\right)_{3}-\mathrm{NH}-\right) ; 6.02(\mathrm{~d}, \mathrm{~J}=5.49 \mathrm{~Hz} ; 1 \mathrm{H}$, $\left.-\mathrm{NH}-\mathrm{CH}\left(\mathrm{CH}_{3}\right)-\right) ; 4.11(\mathrm{~d}, \mathrm{~J}=16.14 \mathrm{~Hz} ; 1 \mathrm{H},-\mathrm{CO}-\mathrm{CHH}-) ; 3.94(5)$ and $3.94(0)\left(\mathrm{s}+\mathrm{s} ; 3 \mathrm{H}, \mathrm{CH}_{3}-\mathrm{O}-\right) ; 3.84$ and $3.83(\mathrm{t}+\mathrm{t}, \mathrm{J}=4.64 \mathrm{~Hz}$, $\left.\mathrm{J}=4.66 \mathrm{~Hz} ; 1 \mathrm{H},-\mathrm{CO}-\mathrm{CH}\left(\mathrm{CH}_{2}-\right)-\mathrm{NH}-\right) ; 3.66-3.62(\mathrm{~m} ; 1 \mathrm{H},-\mathrm{NH}-$ $\left.\mathrm{CH}\left(\mathrm{CH}_{3}\right)^{-}\right) ; 3.50(\mathrm{~d} ; \mathrm{J}=16.14 \mathrm{~Hz} ; 1 \mathrm{H},-\mathrm{CO}-\mathrm{CHH}-) ; 3.30-3.24(\mathrm{~m}$; $\left.2 \mathrm{H},-\mathrm{CH}_{2}-\mathrm{Ph}\right) ; 3.16-3.04\left(\mathrm{~m} ; 2 \mathrm{H},-\left(\mathrm{CH}_{2}\right)_{2}-\mathrm{CH}_{2}-\right) ; 1.80-1.52(\mathrm{~m}$; $\left.13 \mathrm{H},-\mathrm{CH}_{2}-\mathrm{CH}_{2}-\mathrm{CH}_{2}-,-\left(\mathrm{CH}_{2}\right)_{4}{ }^{-},-\mathrm{CH}\left(\mathrm{CH}_{2}\right)-\mathrm{NH}-\right) ; 1.36$ and 1.35 $\left(\mathrm{d}+\mathrm{d}, \mathrm{J}=6.30 \mathrm{~Hz}, \mathrm{~J}=6.32 \mathrm{~Hz} ; 3 \mathrm{H},-\mathrm{NH}-\mathrm{CH}\left(\mathrm{CH}_{3}\right)-\right) . \delta_{\mathrm{C}}\left(\mathrm{CDCl}_{3}\right.$, 
$75 \mathrm{MHz}) 175.29$ (-CO-CH(CH $\left.\left.2^{-}\right)-\mathrm{NH}-\right) ; 168.31$ (-NH-CO-CH $\left.2^{-}\right)$; 159.37 (QC6); 144.70 (QC2); 144.05 (QC8); 136.25 (ArC1); 135.14 (QC4); 134.97 (QC10); 129.87 (QC9); 129.77 (ArC3); 129.74 (ArC6); $128.57(\mathrm{ArC2}+\mathrm{ArC7}) ; 127.08(\mathrm{ArC4}) ; 121.78(\mathrm{QC3})$; 96.76 (-CO$\left.\mathrm{CH}\left(\mathrm{CH}_{2-}\right)^{-}\right)$; 91.58 (QC7); 86.14 and 86.13 (QC5); 58.77 and 58.76 $\left(-\mathrm{N}(\mathrm{CO}-)-\mathrm{C}\left(-\mathrm{CH}_{2}-\right)-\right)$; $55.14\left(\mathrm{CH}_{3}-\mathrm{O}-\right)$; $47.64\left(-\mathrm{NH}-\mathrm{CH}\left(\mathrm{CH}_{3}\right)-\right)$; $44.32\left(-\mathrm{NH}-\mathrm{CO}-\mathrm{CH}_{2}-\right)$; $39.20\left(-\left(\mathrm{CH}_{2}\right)_{2}-\mathrm{CH}_{2}-\right)$; $36.82\left(-\mathrm{CH}_{2}-\mathrm{Ph}\right)$; 35.71 and $35.69\left(-\mathrm{CH}_{2}-\left(\mathrm{CH}_{2}\right)_{3}-\right)$; $34.66\left(-\mathrm{CH}_{2}-\left(\mathrm{CH}_{2}\right)_{2}-\right)$; 33.82 and $33.80\left(-\left(\mathrm{CH}_{2}\right)_{3}-\mathrm{CH}_{2}-\right) ; 26.20$ and $26.16\left(-\mathrm{CH}_{2}-\mathrm{CH}_{2}-\mathrm{CH}_{2}-\right) ; 22.99$ $\left(-\mathrm{CH}_{2}-\mathrm{CH}_{2}-\left(\mathrm{CH}_{2}\right)_{2}-\right) ; 22.97\left(-\left(\mathrm{CH}_{2}\right)_{2}-\mathrm{CH}_{2}-\mathrm{CH}_{2}-\right) ; 20.48$ (-NH$\left.\mathrm{CH}\left(\mathrm{CH}_{3}\right)-\right) . \mathrm{C}_{31} \mathrm{H}_{39} \mathrm{~N}_{5} \mathrm{O}_{3}\left(529.31 \mathrm{~g} \mathrm{~mol}^{-1}\right): \mathrm{m} / z\left(\mathrm{MH}^{+}\right)=530.60 ; \mathrm{m} / z$ $\left(\mathrm{MNa}^{+}\right)=552.48$.

3-\{7-[(6-Methoxyquinolin-8-yl)amino]-3-aza-2-oxooctyl\}-3-benzyl1,4-diazaspiro[4.6]undecan-2-one, 5s. Yield 34\%; $\delta_{\mathrm{H}}\left(\mathrm{CDCl}_{3}, 300 \mathrm{MHz}\right)$ 8.51 (d, J = 3.85 Hz; 1H, Q2); 7.90 (d, J = 8.21 Hz; 1H, Q4); 7.31-7.15 (m; 6H, Q3, Ar2-6); 6.32 (bs; 1H, Q5); 6.26 (bs; $1 \mathrm{H}, \mathrm{Q7}$ ); 6.08 (d, J = 6.11 Hz; $\left.1 \mathrm{H},-\mathrm{NH}-\mathrm{CH}\left(\mathrm{CH}_{3}\right)-\mathrm{CH}_{2}-\right) ; 6.00\left(\mathrm{t}, \mathrm{J}=5.86 \mathrm{~Hz} ; 1 \mathrm{H},-\mathrm{NH}-\mathrm{CO}-\mathrm{CH}_{2}-\right)$; 3.99 (d, J = $15.86 \mathrm{~Hz}$; $1 \mathrm{H},-\mathrm{NH}-\mathrm{CO}-\mathrm{CHH}-$ ); 3.87 (s; 3H, $\mathrm{CH}_{3}-\mathrm{O}-$ ); 3.79$3.76\left(\mathrm{~m} ; 1 \mathrm{H},-\mathrm{NH}-\mathrm{CH}\left(\mathrm{CH}_{3}\right)-\mathrm{CH}_{2}-\right) ; 3.62-3.58\left(\mathrm{~m} ; 1 \mathrm{H},-\mathrm{CO}-\mathrm{CH}\left(\mathrm{CH}_{2}-\right.\right.$ )-NH-); $3.58(\mathrm{~d}, \mathrm{~J}=15.80 \mathrm{~Hz} ; 1 \mathrm{H},-\mathrm{NH}-\mathrm{CO}-\mathrm{CHH}-) ; 3.27-2.96(\mathrm{~m} ; 4 \mathrm{H}$, $\left.-\left(\mathrm{CH}_{2}\right)_{2}-\mathrm{CH}_{2}-,-\mathrm{CH}_{2}-\mathrm{Ph}\right) ; 1.85$ (bs; $\left.1 \mathrm{H},-\mathrm{CO}-\mathrm{CH}\left(\mathrm{CH}_{2}-\right)-\mathrm{NH}-\right) ; 1.67-$ $\left.1.40\left(\mathrm{~m} ; 16 \mathrm{H},-\mathrm{CH}_{2}-\mathrm{CH}_{2}-\mathrm{CH}_{2-},-\left(\mathrm{CH}_{2}\right)_{6}\right)^{-}\right) 1.28(\mathrm{~d}, \mathrm{~J}=6.32 \mathrm{~Hz} ; 3 \mathrm{H}$, $\left.-\mathrm{NH}-\mathrm{CH}\left(\mathrm{CH}_{3}\right)-\mathrm{CH}_{2}-\right) . \delta_{\mathrm{C}}\left(\mathrm{CDCl}_{3}, 75 \mathrm{MHz}\right) 175.28\left(-\mathrm{CO}-\mathrm{CH}\left(\mathrm{CH}_{2}\right)-\mathrm{NH}-\right.$ ); 169.09 (-NH-CO-CH $\left.{ }_{2}^{-}\right) ; 159.85$ (QC6); 145.37 and 145.35 (QC2); 144.74 and 144.72 (QC8); 136.87 (ArC1); 135.77 (QC4); 135.19 (QC10); 130.32 (QC9); 130.31 (ArC3); 130.27 (ArC5); 129.02 (ArC2); 129.01 (ArC6); 127.55 (ArC4); 122.29 (QC3); 97.11 (QC7); 92.09 (QC5); 82.28 (-CO-CH(CH$\left.\left.{ }_{2}^{-}\right)-\mathrm{NH}-\right)$; $58.68\left(-\mathrm{N}-\mathrm{C}\left(-\mathrm{CH}_{2}-\right)-\mathrm{NH}-\right)$; $55.63\left(\mathrm{CH}_{3}-\mathrm{O}-\right)$; $48.14\left(-\mathrm{NH}-\mathrm{CH}\left(\mathrm{CH}_{3}\right)-\mathrm{CH}_{2}-\right) ; 45.33\left(-\mathrm{NH}-\mathrm{CO}-\mathrm{CH}_{2}-\right) ; 40.58$ and 40.55 $\left(-\mathrm{CH}_{2}-\mathrm{Ph}\right)$; 39.75 and $39.74\left(-\left(\mathrm{CH}_{2}\right)_{2}-\mathrm{CH}_{2}-\right) ; 37.84$ and $37.80\left(-\mathrm{CH}_{2-}\right.$ $\left.\left(\mathrm{CH}_{2}\right)_{5}-\right)$; $36.59\left(-\left(\mathrm{CH}_{2}\right)_{5}-\mathrm{CH}_{2}-\right)$; $34.46\left(-\mathrm{CH}_{2}-\left(\mathrm{CH}_{2}\right)_{2}-\right)$; 29.66 and $29.63\left(-\left(\mathrm{CH}_{2}\right)_{3}-\mathrm{CH}_{2}-\left(\mathrm{CH}_{2}\right)_{2}-\right) ; 29.32$ and $29.28\left(-\left(\mathrm{CH}_{2}\right)_{2}-\mathrm{CH}_{2}-\left(\mathrm{CH}_{2}\right)_{3}-\right.$ ); $24.78\left(-\mathrm{CH}_{2}-\mathrm{CH}_{2}-\mathrm{CH}_{2}-\right) ; 22.71$ and $22.69\left(-\mathrm{CH}_{2}-\mathrm{CH}_{2}-\left(\mathrm{CH}_{2}\right)_{4}\right)^{-}$; 22.31 and $22.27\left(-\left(\mathrm{CH}_{2}\right)_{4}-\mathrm{CH}_{2}-\mathrm{CH}_{2}-\right)$; $21.04\left(-\mathrm{NH}-\mathrm{CH}\left(\mathrm{CH}_{3}\right)-\mathrm{CH}_{2}-\right)$. $\mathrm{C}_{33} \mathrm{H}_{43} \mathrm{~N}_{5} \mathrm{O}_{3}\left(557.3366 \mathrm{~g} \mathrm{~mol}^{-1}\right): \mathrm{m} / z\left(\mathrm{M}^{+}\right)=557.2182$.

\subsection{Kinetics of hydrolysis}

The kinetics of hydrolysis of imidazolidin-4-ones 5 were studied by HPLC using a Merck Hitachi L-7110 pump with a L-7400 UV detector set at $254 \mathrm{~nm}$, a manual sample injection module equipped with a $20 \mu \mathrm{L}$ loop, a Merck Lichrospher ${ }^{\circledR} 100 \mathrm{RP}_{18}$ $125 \mathrm{~cm} \times 4.6 \mathrm{~mm}(5 \mu \mathrm{m})$ column equipped with a Merck Lichrocart pre-column (Merck, Germany). The kinetics of hydrolysis of imidazolin-4-ones 5 (Scheme 4) were studied at $37.0 \pm 0.1^{\circ} \mathrm{C}$, in aqueous buffers with ionic strength kept at $0.5 \mathrm{M}$ by the addition of $\mathrm{NaClO}_{4}$. The buffers used were acetate ( $\left.\mathrm{pH} 3.0-5.9\right)$, phosphate ( $\mathrm{pH}$ 6.0-7.5), and borate ( $\mathrm{pH} 8.0-11.0$ ). Sodium hydroxide and hydrochloric acid pseudo-buffers were used at $\mathrm{pH}$ higher than 12 and lower than 2, respectively. Typically, reactions were initiated by injecting a $10 \mu \mathrm{L}$ aliquot of a $10^{-2} \mathrm{M}$ stock solution of substrate in acetonitrile to $10 \mathrm{~mL}$ of the appropriate thermostated buffer solution. At regular intervals, samples of the reaction mixture were analyzed using an isocratic solvent system of acetonitrile and sodium acetate buffer ( $\mathrm{pH} 4.75 ; 0.05 \mathrm{M}$ ) containing $10^{-3} \mathrm{M}$ triethylamine. All reactions followed first-order kinetics over four half lives.

\subsection{Hydrolysis in plasma from mice}

Compounds $\mathbf{5 a}, \mathbf{5 b}$ and $\mathbf{5 f}$ were incubated at $37^{\circ} \mathrm{C}$ in plasma obtained from non-infected mice, diluted to $80 \%(\mathrm{v} / \mathrm{v})$ with $\mathrm{pH} 7.4$ isotonic phosphate buffer. At appropriate intervals, aliquots were added to acetonitrile to quench the reaction and precipitate plasma proteins. These samples were centrifuged and the supernatant was analyzed by the HPLC method described above for the presence of substrate and products.

\subsection{In vivo gametocytocidal activity}

BalbC mice were infected by intraperitoneal inoculations of $10^{7}$ erythrocytes parasitized with $P$. berghei ANKA. After 4 days, when the presence of gametocytes and exflagellation was observed by microscopic observation of Giemsa stained blood films, mice were randomly separated into five different groups of six animals. Each group was treated by intraperitoneal administration with one single dose of each compound 5 and primaquine (10 and $50 \mu \mathrm{mol} /$ $\mathrm{kg}$ in inoculation volumes of $0.1-0.2 \mathrm{~mL}$; controls consisted of mice given a PBS solution). Two hours after administration, mice were anesthetized and placed on top of individual cages containing ca. 50 glucose-starved $A$. stephensi female mosquitoes, which were allowed to feed for $2 \mathrm{~h}$. After the blood meal, unfed female mosquitoes were removed from each cage. Ten days after the blood meal, 10 mosquitoes of each cage were randomly collected and dissected for microscopic detection of oocysts in midguts. For further details see ref. [18].

\section{Acknowledgments}

The authors wish to thank FCT for financial support through the research project PTDC/QUI/65142/2006, pluriannual funding to iMed.UL, CIQUP and CMDT-LA, and a Post-Doctoral fellowship to N.V. (SFRH/BPD/48345/2008).

\section{Appendix. Supporting information}

Supporting information associated with this article can be found in the online version, at doi:10.1016/j.ejmech.2009.01.018.

\section{References}

[1] B.L. Tekwani, L.A. Walker, Curr. Opin. Infect. Dis. 19 (2006) 623-631.

[2] R.P. Brueckner, C. Ohrt, J.K. Baird, W.K. Milhous, 8-Aminoquinolines, in: P.J. Rosenthal (Ed.), Antimalarial Chemotherapy: Mechanisms of Action, Resistance and New Directions in Drug Discovery, Humana Press, Totowa, NJ, 2001, pp. 123-151.

[3] S.F. Queener, J. Med. Chem. 38 (1995) 4739-4759.

[4] J.D. Berman, L.S. Lee, Am. J. Trop. Med. Hyg. 32 (1983) 753-759.

[5] R.E. McCabe, J. Parasit. 74 (1988) 748-753.

[6] G.W. Mihaly, S.A. Ward, G. Edwards, M. L'E Orme, A.M. Breckenridge, Br. J. Clin. Pharmacol. 17 (1984) 441-446.

[7] K.J. Baird, S.L. Hoffman, Clin. Infect. Dis 39 (2004) 1336-1345.

[8] J.K. Baker, J.A. Bedford, A.M. Clark, J.D. McChesney, Pharm. Res. 1 (1984) $98-100$.

[9] J.K. Baker, R.H. Yarber, N.P.D. Nanayakkara, J.D. McChesney, F. Homo, I. Landau, Pharm. Res. 7 (1990) 91-95.

[10] L. Constantino, P. Paixão, R. Moreira, M.J. Portela, V.E. Rosário, J. Iley, Exp. Toxic. Pathol. 51 (1999) 299-303.

[11] Y.R. Kim, H.J. Kuh, M.Y. Kim, Y.S. Kim, W.C. Chung, S.I. Kim, M.W. Kang, Arch. Pharm. Res. 27 (2004) 576-580.

[12] D.R. Hill, J.K. Baird, M.E. Parise, L.S. Lewis, E.T. Ryan, A.J. Magill, Am. J. Trop. Med. Hyg. 75 (2006) 402-415.

[13] J. Umbreit, Am. J. Hematol. 82 (2007) 134-144.

[14] S. Noel, S. Sharma, R. Shanker, S.K. Rath, Toxicology 239 (2007) 96-107.

[15] A. Philip, J.A. Kepler, B.H. Johnson, F.I. Carrol, J. Med. Chem. 31 (1988) 870-874.

[16] R. Borissova, P. Stjärnkvist, M.O. Karlsson, I. Sjäholm, J. Pharm. Sci. 84 (1995) 256-262.

[17] M.C. Chung, M.F. Gonçalves, W. Colli, E.I. Ferreira, M.T.M. Miranda, J. Pharm. Sci. 86 (1997) 1127-1131.

[18] M.J. Portela, R. Moreira, E. Valente, L. Constantino, J. Iley, J. Pinto, R. Rosa, P. Cravo, V.E. Rosário, Pharm. Res. 16 (1999) 949-955.

[19] U. Klixbüll, H. Bundgaard, Int. J. Pharm. 20 (1984) 273-284.

[20] G.J. Rasmussen, H. Bundgaard, Int. J. Pharm. 71 (1991) 45-53.

[21] G.J. Rasmussen, H. Bundgaard, Int. J. Pharm. 76 (1991) 113-122.

[22] A. Bak, M. Fich, B.D. Larsen, S. Frokjaer, G.J. Friis, Eur. J. Pharm. Sci. 7 (1999) 317-323.

[23] P. Gomes, M.J. Araújo, M. Rodrigues, N. Vale, Z. Azevedo, J. Iley, P. Chambel, J. Morais, R. Moreira, Tetrahedron 60 (2004) 5551-5562. 
[24] M.J. Araújo, J. Bom, R. Capela, C. Casimiro, P. Chambel, P. Gomes, J. Iley, F. Lopes, J. Morais, R. Moreira, E. Oliveira, V. Rosário, N. Vale, J. Med. Chem. 48 (2005) 888-892.

[25] N. Vale, M.S. Collins, J. Gut, R. Ferraz, P.J. Rosenthal, M.T. Cushion, R. Moreira P. Gomes, Bioorg. Med. Chem. Lett. 18 (2008) 485-488.

[26] P. Chambel, R. Capela, F. Lopes, J. Iley, J. Morais, L. Gouveia, J.R.B. Gomes, P. Gomes, R. Moreira, Tetrahedron 62 (2006) 9883-9891.

[27] N. Vale, J. Matos, J. Gut, F. Nogueira, V. do Rosário, P.J. Rosenthal, R. Moreira P. Gomes, Bioorg. Med. Chem. Lett. 18 (2008) 4150-4153.

[28] M. Bodanszky, Peptide Chemistry - A Practical Textbook, Springer-Verlag, New York, USA, 1988

[29] P. Lloyd-Williams, F. Albericio, E. Giralt, Chemical Approaches to the Synthesis of Peptides and Proteins, CRC Press, Boca Raton, USA, 1997.
[30] A.R. Katritzky, Y.J. Xu, H.Y. He, P.J. Steel, J. Chem. Soc., Perkin Trans. 1 (2001) 1767-1770.

[31] A.P.P. Chevrier, F. Cantagrel, K.L. Jeune, C. Philouze, P.Y. Chavant, Tetrahedron: Asymmetry 17 (2006) 1969-1974.

[32] U. Klixbüll, H. Bundgaard, Int. J. Pharm. 23 (1985) 163-173.

[33] H. Bundgaard, M. Johansen, Arch. Pharm. Chem. Sci. 8 (1980) 29-52.

[34] (a) For Gly-Gly: The Index Merck, eleventh ed. Merck, Rahway, 1989;

(b) For Phe-Gly: A. Yamamoto, Y. Morishita, S. Sogishita, T. Hayami, N. Okada T. Fujita, S. Muranishi Drug Metab. Pharmacokin. 18 (2003) 23-32.

[35] R.E. Coleman, A.M. Clavin, W.K. Milhous, Am. J. Trop. Med. Hyg. 46 (1992) $169-182$.

[36] R.E. Coleman, A.K. Nath, I. Schneider, G.H. Song, T.A. Klein, W.K. Milhous, Am. J. Trop. Med. Hyg. 50 (1994) 646-653. 